\title{
Hydrogen from Biomass for Urban Transportation
}

\section{FINAL REPORT}

\author{
Report Prepared by: \\ William Boone, Principal Investigator \\ Clark Atlanta University, Atlanta, GA 30314 \\ Email: wboone@cau.edu; Tel. 404.880.8972
}

\author{
Members of the consortium during project period were: \\ Clark Atlanta University (Lead), Atlanta, GA \\ Georgia Institute of Technology, Atlanta, GA \\ Scientific Carbons Inc. Blakely, GA \\ Enviro-Tech Enterprises Inc. Matthews, NC \\ National Renewable Energy Lab, Golden, C0
}

DOE Award Number: DE-FC36-00G010528

Submitted by: Clark Atlanta University, Atlanta, GA 30314

Eprida Scientific Carbons Inc., Atlanta, GA

February 18, 2008 


\section{TABLE OF CONTENTS}

$\begin{array}{ll}\text { Executive Summary } & 1\end{array}$

$\begin{array}{ll}\text { Introduction } & 1\end{array}$

Overall Objective $\quad 1$

Overall Project Performance $\quad 1$

Summary of Accomplishments $\quad 2$

$\begin{array}{ll}\text { References } & 3\end{array}$

\section{Appendices}

Appendix A: Hydrogen from Biomass for Urban Transportation Semiannual Progress Report, October 2002 to March 2003

Appendix B: Hydrogen from Biomass for Urban Transportation Semiannual Progress Report, April 2003 to September 2003

Appendix C: Hydrogen from Biomass for Urban Transportation Semiannual Progress Report, October 2003 to March 2004

Appendix D: Hydrogen from Biomass for Urban Transportation Annual Progress Report, July 2004 to July 2005

Appendix E: Hydrogen from Biomass for Urban Transportation Final Schedule of Eprida Activities October 2005 to September 2007

Appendix F: Sample Data from 1,000 hour long term study 


\section{Executive Summary}

The objective of this project was to develop a method, at the pilot scale, for the economical production of hydrogen from peanut shells. During the project period a pilot scale process, based on the bench scale process developed at NREL (National Renewable Energy Lab), was developed and successfully operated to produce hydrogen from peanut shells. The technoeconomic analysis of the process suggests that the production of hydrogen via this method is cost-competitive with conventional means of hydrogen production.

\section{Introduction}

Biomass can be converted to hydrogen by two distinct strategies: 1) gasification followed by shift conversion and 2) pyrolysis of biomass to form bio-oil that can be subsequently converted to hydrogen via catalytic steam reforming and shift conversion. The project used the latter approach, because this approach has the potential to be cost competitive with current commercial processes for hydrogen production [1]. The process was demonstrated at the bench scale at the National Renewable Energy Lab (NREL) using model compounds and the carbohydrate-derived fraction of bio-oil [2,3]. This approach has several advantages over the traditional gasification technology. Bio-oil is transportable, so the second step (steam reforming) can be carried out at a different location, close to the existing infrastructure for hydrogen use and distribution. Another advantage of this process is the production and recovery of higher-value co-products from bio-oil that could significantly impact economics of the entire process.

This project focused on the use of peanut shells to produce hydrogen for urban transportation using pyrolysis-reforming technology. Specifically, a pilot scale reactor at Eprida Scientific Carbons, Inc., a small company in Georgia, that produces activated carbon by pyrolysis of densified peanut shells, was used to test the overall objective of the project.

\section{Overall Objective}

The overall objective was to undertake the engineering research and pilot scale process development studies to economically produce hydrogen from biomass such as peanut shells.

\section{Overall Project Performance}

To accomplish the overall objective of the project, the project was divided into three phases:

Phase 1 of the project was process development studies in the use of large quantities of peanut shells produced in Georgia as feedstock for the proposed pyrolysis-steam reforming process. The method combines two stages: slow pyrolysis of biomass to generate charcoal and catalytic reforming of the pyrolysis vapors to hydrogen and carbon dioxide. The catalytic reactor was successfully constructed and tested at NREL during Phase 1.

Phase 2 of the project was the integration of a pilot scale version of the pyrolyzer used for making activated carbon from densified peanut shells at Scientific Carbons Inc. with the steam reformer designed and constructed in Phase 1 . Phase 2 of the studies included the long term catalyst testing which was accomplished by operating the pilot unit for 100 hours. 
Phase 3 of the project was carried out to experimentally determine catalysts performance, rate of degradation, and regenerative capacity under specified operating conditions. This was accomplished by completing the 1000 hour run to study catalyst deactivation and regeneration performance.

\section{Results}

This section summarizes the overall results which are detailed in Appendices A through $\mathrm{F}$. The section outlines the results and the report readers are appropriately referenced to appendices for design, result and performance details.

The overall objective of the project was successfully accomplished when the total run time of the pilot plant since the project's initiation passed the 1000 hour benchmark. (See Appendix E, p.1). The photo of the pilot plant is shown in Figure 2 of Appendix D p.5 and the overall schematic flow diagram of the biomass pyrolysis-reformer process is shown in Figure 2 of Appendix D p. 4. The pilot scale hydrogen production plant from biomass operated via integrated pyrolysis and fluidized catalytic reforming.

During the 100 hours of operation of experiment, $57 \%$ (at dry $\mathrm{N}_{2}$-free basis) of hydrogen was obtained from the integrated process, with the pyrolysis of the biomass at $450^{\circ} \mathrm{C}$ and the reforming temperature of pyrolysis gas at $850^{\circ} \mathrm{C}$, respectively. Using peanut shells as feedstock, the overall yield from this process is up to $7 \mathrm{wt} \%$ hydrogen and $32 \mathrm{wt} \%$ charcoal/activated carbon. Appendix $F$ shows the experimental output of the production of hydrogen (and other gases) as a function of time. The complete data is available in the CD included with this report. The preliminary techno-economic analysis indicates that this integrated process has potential of producing hydrogen at the cost of about US $\$ 7 / G J$ with an assumed facility of daily hydrogen production rate of 50 tons (the reader is recommended to read pages 4-8 in Appendix D).

\section{Summary of Accomplishments}

We have successfully developed an integrated process of pyrolysis of biomass and reforming of the pyrolysis gas for hydrogen production at the pilot scale. A major milestone of the project was the recent completion of a 1000 hour operation of the pilot plant and to study/evaluate catalyst deactivation and regeneration. The ultimate goal was successfully accomplished by demonstrating the feasibility and tremendous potential of producing hydrogen from peanut shells. The pilot plant that was built for this process has increased the hydrogen production rate; further, results indicate that the yields at the pilot scale and the bench scale are comparable.

The project has:

- Completed integration and 100 hours of successful operation of pyrolysis-reformer pilot unit (Phase 2).

- Completed the 1,000 hour long term pilot operation of the pilot plant (Phase 3).

- Conducted an analysis of the economic potential of producing hydrogen from peanut shells.

Overall, the developed process shows the potential of being cost-competitive with those conventional means of hydrogen production. 


\section{References}

1. Mann, M.K. 1995. "Technical and economic analyses of hydrogen production via indirectly heated gasification and pyrolysis," in Proceedings of the 1995 Hydrogen Program Review, Vol. 1, NREL/CP-430-20036-Vol. 1, pp. 205-236.

2. Wang, D., Czernik, S., Montane, D., Mann, M., Chornet, E., 1997, I\&EC Research, 36, 1507-1518.

3. Wang, D., Czernik, S., Chornet, E., 1997, "Production of Hydrogen from Biomass by Catalytic Steam Reforming of Fast Pyrolysis", Energy \& Fuels, 12, 19-24. 
APPENDICES 


\title{
Hydrogen from Biomass for Urban Transportation
}

\author{
Y. D. Yeboah (PI), K. B. Bota and Z. Wang \\ Clark Atlanta University, Atlanta, GA 30314 \\ Email: vyeboah@cau.edu; Phone: 404-880-6619 \\ M. Realff \\ Georgia Institute of Technology, Atlanta, GA \\ D. Day and J. Howard \\ Scientific Carbons Inc, Blakely, GA \\ D. McGee \\ Enviro-Tech Enterprises Inc, Matthews, NC
}

R. Evans, E. Chornet, S. Czernik, C. Feik, R. French, S. Phillips, J. Patrick, L. Boyd and C. Elam

National Renewable Energy Lab, Golden, CO

Semiannual Progress Report for the Period October 2002 to March 2003 


\section{INTRODUCTION}

Hydrogen is the most environmentally friendly fuel and can be efficiently used for stationary power and mobile applications. When burned or oxidized, it generates water as the only emission (small amounts of NOx are generated during the combustion process but can be controlled to very low levels). At present, hydrogen is produced almost entirely from fossil fuels such as natural gas, naphtha, and coal. During these hydrogen production processes, large amounts of fossil-derived $\mathrm{CO}_{2}$ are released to the atmosphere. Renewable biomass is an attractive alternative to fossil feedstocks because of essentially zero net $\mathrm{CO}_{2}$ impact [1].

Biomass is defined as a material that has participated in the "growing cycle." Agriculture waste, forest residue, urban wood waste, and trees and grasses grown as energy crops are materials commonly referred to as biomass. Because biomass consumes as much $\mathrm{CO}_{2}$ in the growing cycle as is produced when it is transformed into energy, the net $\mathrm{CO}_{2}$ contribution from biomassderived fuels is considerably less than from fossil-derived fuels. In addition, producing biomass on a sustainable basis by growing energy crops will support the agricultural sector of states such as Georgia. Successful use of biomass to generate hydrogen for transportation will also reduce oil and gas imports of the U.S. [1].

Agriculture is Georgia's largest industry and contributes over $\$ 46$ billion to the state's annual economic output. One in six Georgians work in an agriculture-related sector. Georgia ranks as the number one state in the U.S. in peanut production, producing about $45 \%$ of all peanuts grown in the U.S. Georgia farmers grow about 1.5 billion pounds of peanut in 79 counties annually. Disposal of the large quantity of peanut shells in an environmentally acceptable manner is a significant challenge for the peanut industry. Hence, peanut shells have been targeted as the biomass feedstock for conversion to hydrogen for urban transportation in this project.

The National Renewable Energy Laboratory (NREL) in Golden, $\mathrm{CO}$ has developed the basis of a technology for the generation of hydrogen from biomass and agricultural residue [2,3]. Biomass can be converted to hydrogen by two distinct strategies: 1) gasification followed by shift conversion and 2) pyrolysis of biomass to form a bio-oil that can be subsequently converted to hydrogen via catalytic steam reforming and shift conversion. The NREL technology uses the latter approach, which has the potential to be cost competitive with current commercial processes for hydrogen production [4]. The process has been demonstrated at the bench scale using model compounds and the carbohydrate-derived fraction of bio-oil [2,3]. This concept has several advantages over the traditional gasification technology. Bio-oil is easily transportable so the second step (steam reforming) can be carried out at a different location, close to the existing infrastructure for hydrogen use or distribution. The second advantage is the potential for production and recovery of higher-value co-products from bio-oil that could significantly impact the economics of the entire process.

The hydrogen content in biomass is reiatively low (6-6.5\%), compared to almost $25 \%$ in natural gas. For this reason, producing hydrogen via the biomass gasification/water-gas shift process cannot compete on a cost basis with the well-developed commercial technology for steam reforming of natural gas. However, an integrated process, in which part of the biomass is used to produce more valuable materials or chemicals and the residual fractions are used to generate hydrogen, can be an economically viable option. 
In the previous NREL work, it was demonstrated, initially through micro-scale tests then in the bench-scale fixed-bed reactor experiments $[2,5,6]$, that bio-oil model compounds as well as the carbohydrate-derived fraction of bio-oil can be efficiently converted to hydrogen. Using commercial nickel catalysts the hydrogen yields obtained exceeded $90 \%$ of the possible stoichiometric conversion. The carbohydrate-derived bio-oil fraction contains a substantial amount of non-volatile compounds (sugars, oligomers), which tend to decompose thermally and carbonize before contacting the steam reforming catalyst. The prior studies managed to reduce these undesired reactions by injecting the oil fraction to the reactor in a form of a fine mist. However, the carbonaceous deposits on the catalyst and in the reactor freeboard made most of the catalyst inaccessibie to contact with the oil limiting the reforming time to 3-4 hours. For the above reasons, NREL decided to employ a different reactor configuration, a fluidized bed, to overcome at least some limitations of the fixed-bed unit. This greatly increased the reforming efficiency and extended the catalyst time-on-stream. Catalyst regeneration was done by steam or carbon dioxide gasification of carbonaceous residues providing additional amounts of hydrogen. Details of the fluidized-bed experiments at NREL with pelletized peanut shells from Scientific Carbons Inc. in Blakely, Georgia, which proved to be encouraging may be found elsewhere $[2,3,5,6]$.

The economics of the proposed approach was assessed with an adhesive coproduct and the selling price of hydrogen was determined to be in the range of \$6-8/MBTU [4]. Capital costs were scaled from Mann [4] using a 0.84 exponent. This exponent was derived from the three cases presented in Mann [4]. Fixed operating costs and working capital were also based on the paper. Variable operating costs were determined from the material balance. The pyrolysis vapor was assumed to be available at $\$ 2.56 / \mathrm{GJ}$, a value that is roughly $90 \%$ of its fuel value (assuming an energy equivalence to natural gas at $\$ 2.50 / \mathrm{GJ}$ ). The analysis also assumed that steam would be produced in the reforming operation. A credit based on $\$ 3.50 / 1000$ lbs of steam was assumed.

Using the above assumptions, the total capital investment for the additional equipment to modify the existing facility to produce hydrogen from the pyrolysis off-gas was estimated at $\$ 1.4$ million. For an annual hydrogen production rate of 4.4 million $\mathrm{Nm}^{3}$, the selling price of hydrogen was estimated to be $\$ 9.51 / \mathrm{GJ}$. The hydrogen-selling price for a fuel cost of $\$ 1.28 / \mathrm{GJ}$ (i.e., $45 \%$ fuel value) was $\$ 7.78 / G J$. Using a no-cost bio-oil the selling price for the hydrogen was predicted as $\$ 6.05 / G J$. These price ranges are very promising considering that the economics were performed for a very small-scale operation.

Recent estimates give target costs of hydrogen production from biomass as $\$ 3.80 / \mathrm{kg} \mathrm{H}_{2}$ in $2003, \$ 2.90 / \mathrm{kg} \mathrm{H} \mathrm{H}_{2}$ in 2010 and $\$ 2.30 / \mathrm{kg} \mathrm{H}$.

Based on the potential technical and economic advantages of the process, Phases 1 and 2 of the project focused on undertaking the engineering research and development studies that would lead to the long term testing of the catalyst and process. 


\section{PROGRAM GOALS AND OBJECTIVES}

The project focuses on the use of agricultural residues such as peanut shells to produce hydrogen for urban transportation. Specifically, a pilot-scale reactor on site at Eprida Scientific Carbons Inc., a small company in Blakely, Southwest Georgia, that produces activated carbon by pyrolysis of densified peanut shells, is being used to test the concept. The primary focus of Phase 1 of the project was to undertake process development studies in the use of the large quantities of peanut shells produced in Georgia as feedstock for the proposed pyrolysis-steam reforming process. The method combines two stages: slow pyrolysis of biomass to generate charcoal and catalytic steam reforming of the pyrolysis vapors to hydrogen and carbon dioxide. Scientific Carbons Inc. is currently operating a commercial facility in Blakely, GA, to convert 24 tons/day of pelletized peanut shells to activated carbon. Scientific Carbons' pilot-scale reactor, which has a feed rate of $50 \mathrm{~kg} /$ hour, is being used in the Phase 2 of the project to perform a demonstration of a steam reforming process to convert the off-gas of the peanut-shell carbonization process to hydrogen. As a small company with the demonstrated ability to build modular systems, their current process could be modified and expanded to run a variety of other feedstocks and to make a range of alternative products. In Phase 1 we focused on development of decision models for selecting feedstock, process and alternatives, and designed and managed the construction of a $10-20 \mathrm{~kg} / \mathrm{hr}$ fluidized-bed catalytic steam reformer system. The catalytic reactor system was successfully constructed and tested at NREL during Phase 1.

The emphasis in Phase 2 of the project was on the integration of a pilot scale version of the pyrolyzer used for making activated carbon from densified peanut shells at Scientific Carbons Inc in Southwest Georgia with the steam reformer designed and constructed in Phase 1. The major tasks included: 100 hours catalyst testing of the reformer with the slow pyrolysis byproduct vapors; modeling of the feedstock supply, process economics and deployment strategies; coproducts development and experiments; hydrogen storage and utilization; and partnership building and outreach activities. Thus, Phase 2 involved the engineering research and pilot-scale process development studies in the use of the large quantities of peanut shells produced in Georgia as feedstock for the pyrolysis-steam reforming process to produce hydrogen for urban transportation. The specific Phase 2 project objectives included:

- Development of decision models for selecting feedstock, process and alternatives and measurement and development of solubility and physical properties of the coproducts;

- Design, construction and testing of the pilot scale pyrolyzer at Eprida Scientific Carbons Inc.;

- Completion of the reformer shakedown at NREL's Thermochemical Users Facility, shipping of the unit to Eprida Scientific Carbons and integration of the reformer with the pilot scale pyrolyzer and analytical facilities;

- Completing the shakedown of the pyrolyzer-reformer system and undertaking the long term catalyst activity testing at Eprida Scientific Carbons Inc.;

- Undertaking the design of a separation and storage system for hydrogen and developing analytical systems for monitoring transportation system performance;

- Development of partnerships/collaborations for future transportation demonstration, use of other feedstocks, and development of new processes and markets for the coproducts; and

- Education and training of students, especially underrepresented minorities, in the subject area.

During the reporting period, Phase 2 was completed and a continuation proposal for Phase 3 was submitted and approved. The Phase 3 award is for the budget period February 1, 2003 to March 31, 2004. 


\section{STATUS AND ACCOMPLISHMENTS OF PROGRESS}

Below is a summary of the progress and accomplishments made during the semiannual reporting period.

- Continued developing a model of network of process steps to account for feedstock, location, process, and the uncertainties in these factors.

- Collected bio-oil and determined solubility parameters and physical property estimation methods of the components of the bio-oil product of peanut shell pyrolysis.

- Completed system modifications, integration and 100-hour pyrolysis-reformer run for long term catalyst testing of process

- Completed analysis of the data for the 100-hour long term catalyst testing

- Identified potential agricultural uses of the carbon product from the pyrolysis

- Developed plans for 1,000 hours long term testing of the catalyst and process for Phase 3

- Initiated partnership and collaboration with the University of Georgia, Athens, to move the pyrolysis-reformer pilot unit to their Bioconversion Center facilities in Athens, GA

- Initiated evaluation of approaches to hydrogen separation and storage including pressure swing adsorption (PSA) and Quantum's technology for hydrogen storage.

- Held Phase 3 project review meetings at Clark Atlanta University and the University of Georgia, Athens. All other communications among the project team were by conference calls.

- Prepared material for the Annual Hydrogen, Fuel Cells and Infrastructure Merit Review meeting in Berkeley, CA, to be held on May 18-22, 2003

Details on some of the above summary points are provided below.

Task I: Feedstock supply, process economics, and deployment strategies (Modeling, extraction and property estimation)

Literature data and thermodynamic models were employed to evaluate a large number of organic solvents for the extraction of phenol from aqueous bio-oils. Several good solvents were identified and extractions were carried out on bio-oil samples provided by NREL [7].

\section{Solvent selection}

\section{Based on ternary liquid-liquid equilibria (LLE) data}

Sets of LLE data for systems of the type phenol + water + solvent were obtained from the literature. The solvents included 7 acetates (from ethyl acetate to hexyl acetate), 6 aromatics (benzene, ethylbenzene, propylbenzene, nitrobenzene, aniline, and naphthalene), 2 ketones (acetone and methyl isobutyl ketone, MIBK), and 2 alcohols (methanol and 2-propanol). Solvent selectivities $\beta=\left(X_{\text {phenol }} / X_{\text {water }}\right)^{\text {solvent }} /\left(X_{\text {phenol }} / X_{\text {water }}\right)^{\text {water }}$ and distribution coefficients $K=$ $\left(X_{\text {phenol }}\right)$ solvent / $\left(X_{\text {phenol }}\right)^{\text {water }}$ were calculated from tie-line data. Isopropyl acetate (IPA) exhibited the highest values of both $\beta$ and $K$, followed by MIBK. Benzene exhibited the lowest values, and is therefore unlikely to be a good solvent for extracting phenol, particularly at low phenol concentrations in the aqueous phase. Both IPA and MIBK were identified as good solvents for extracting phenol. No ternary LLE data were found for systems involving solvents such as halogenated alkanes, ethers, alcohols, or organic acids. Since these solvents are widely used in practical extractions, binary data and thermodynamic models were employed to generate tie lines in these systems. 


\section{Based on binary data and models}

Limiting values of the selectivity $\beta$ were calculated in 500 solvents using infinite dilution activity coefficients $\gamma^{\infty}$. In particular, $\beta^{\infty}{ }_{12}$ and $\beta^{\infty}{ }_{31}$ (where subscript $1=$ phenol, $2=$ water, and $3=$ solvent) were calculated as follows:

$$
\begin{aligned}
& \beta^{\infty}{ }_{12}=500 \times\left(\gamma_{\text {wat }}\right)^{\text {sol }} /\left(\gamma_{\text {phe }}^{\infty}\right)^{\text {sol }} \\
& \beta^{\infty}{ }_{31}=500 /\left(\gamma_{p}^{\infty}\right)^{\text {sol }} /\left(\gamma_{s}^{\infty}\right)^{\text {wat }}
\end{aligned}
$$

Activity coefficients were obtained from the literature, or calculated from LLE data. In the absence of experimental data, they were predicted using the UNIFAC model.

About 500 solvents were evaluated via equations (1) and (2). The solvents included n-alkanes, n-alkanols, alkenes, ethers, acids, aromatics, ketones, and acetates. Alkanediols, amines and halogenated alkanes could not be evaluated due to a lack of UNIFAC coefficients. Propyl acetate and MIBK were identified as good solvents as a result of this evaluation.

\section{Bio-oil Extraction Experiments}

Initial extractions of bio-oil samples supplied by NREL were carried out in a bench-scale apparatus. Propyl acetate (PA) and MIBK were used as the solvents in the extractions. The biooil samples consisted of hard wood oil (sample A) and pure whole oil (sample B). The apparatus was used both for vacuum stripping of the oil and for extractions. Vacuum stripping was carried out to remove volatile compounds. The stripped oil was then contacted with water and the solvent (PA or MIBK). The resulting phases were collected, and the aqueous phase was further contacted with additional solvent. Resulting phases were again collected and are currently being analyzed.

Task 2: Reactor modifications and shakedown

Modifications in the pyrolyzer and reformer were made and the entire system, including the pyrolyzer, reformer, and analytical instruments were integrated and tested for the long-term tests. The pyrolyzer unit achieves its heat requirements through the use of a rich burning natural gas burner. Oxygen levels are monitored to maintain stoichiometric operating conditions inside the pyrolysis unit. The throughput is controlled through a combination of temperature measurements of final char, the off-gas temperature and the temperature of the final combusted gas exhaust. These inputs along with others are connected to two 8-channel Watlow Anafaze controllers, which maintain feed rate and temperature requirements to produce a stable pyrolysis off gas. The pyrolysis unit has 18 thermocouples linked to a computer for tracking as well as a differential pressure gauge to measure the pressure drop across the bed.

The off gas is flared to a continuous pilot burner. A fraction of the off-gas is educted by super heated steam into a ceramic baghouse filter system to remove small carbon particles from the gas stream. This clean gas is then fed to a $12 \mathrm{~kW}$ superheater, which takes the combined pyrolysis gas and supersteam up to 700 degrees $\mathrm{C}$. The gas stream is then fed into the bottom of the steam reformer. The hydrogen gas from the steam reformer is routed through a ceramic baghouse and a condenser to remove any particulate nickel dust and moisture.

Figure 1 shows the pilot unit and some components including the flares from the pyrolyzer and reformer. 

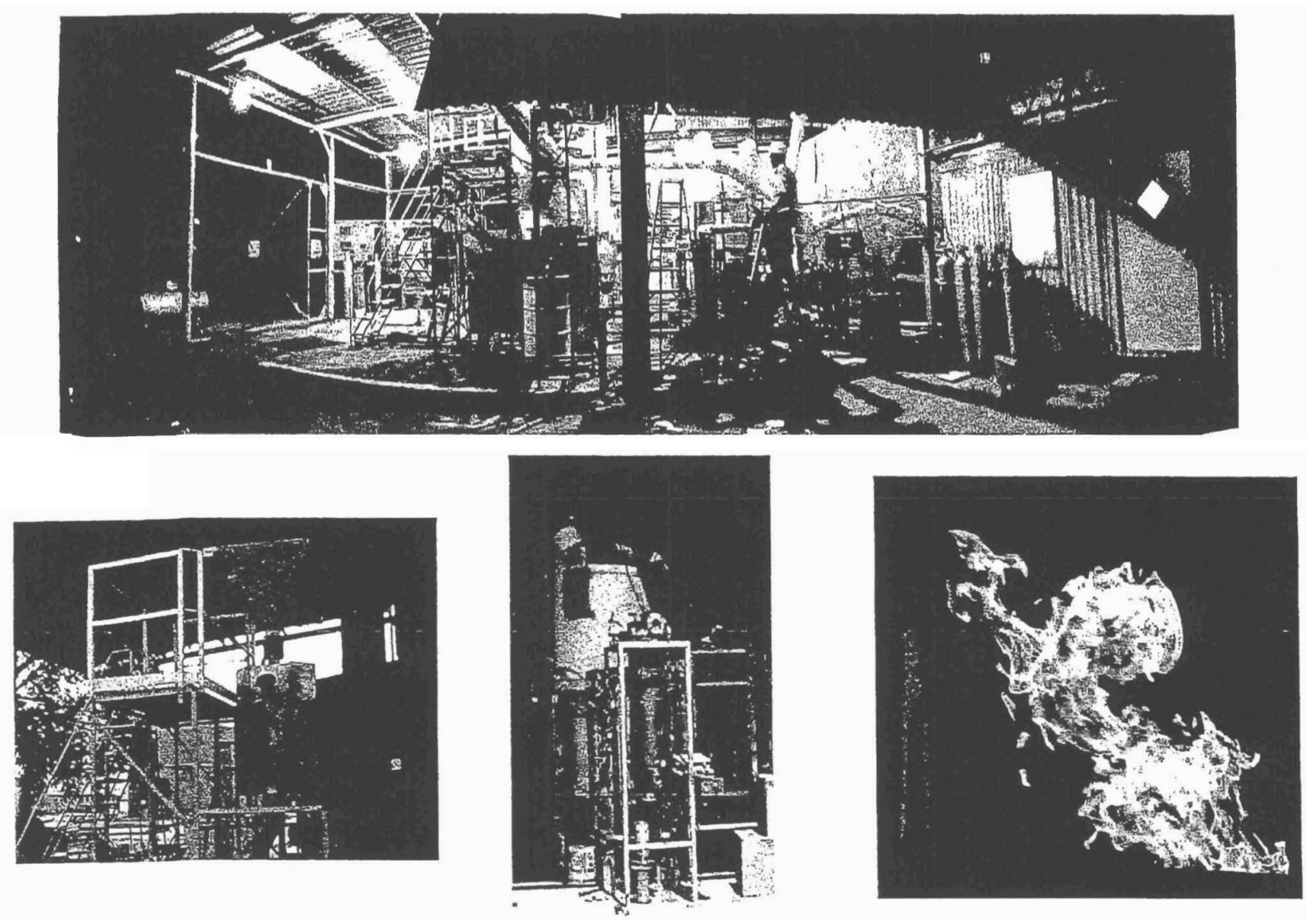

Figure 1 Pictures of the pilot plant unit, components and flares

Task 3: Long term catalyst testing

The pilot unit was operated for 100 hours for the long term catalyst testing. Shown in Figure 2 are the temperature and pressure drop profiles for the reformer over the run duration. Figures 3 and 4 give the reformer gas composition profiles during the run. Also shown in Table 1 are the yields and average reformer gas composition.

Task 4: Hydrogen separation, storage and utilization

The current effort in hydrogen separation is focused on the use of pressure swing adsorption (PSA) for the separation of the hydrogen from carbon dioxide. After the baghouse and condenser, the reformer gas will be dried and compressed before being sent to the PSA system. The current short-term plans are to use an accumulator to store the hydrogen before sending it into an engine for performance testing. 


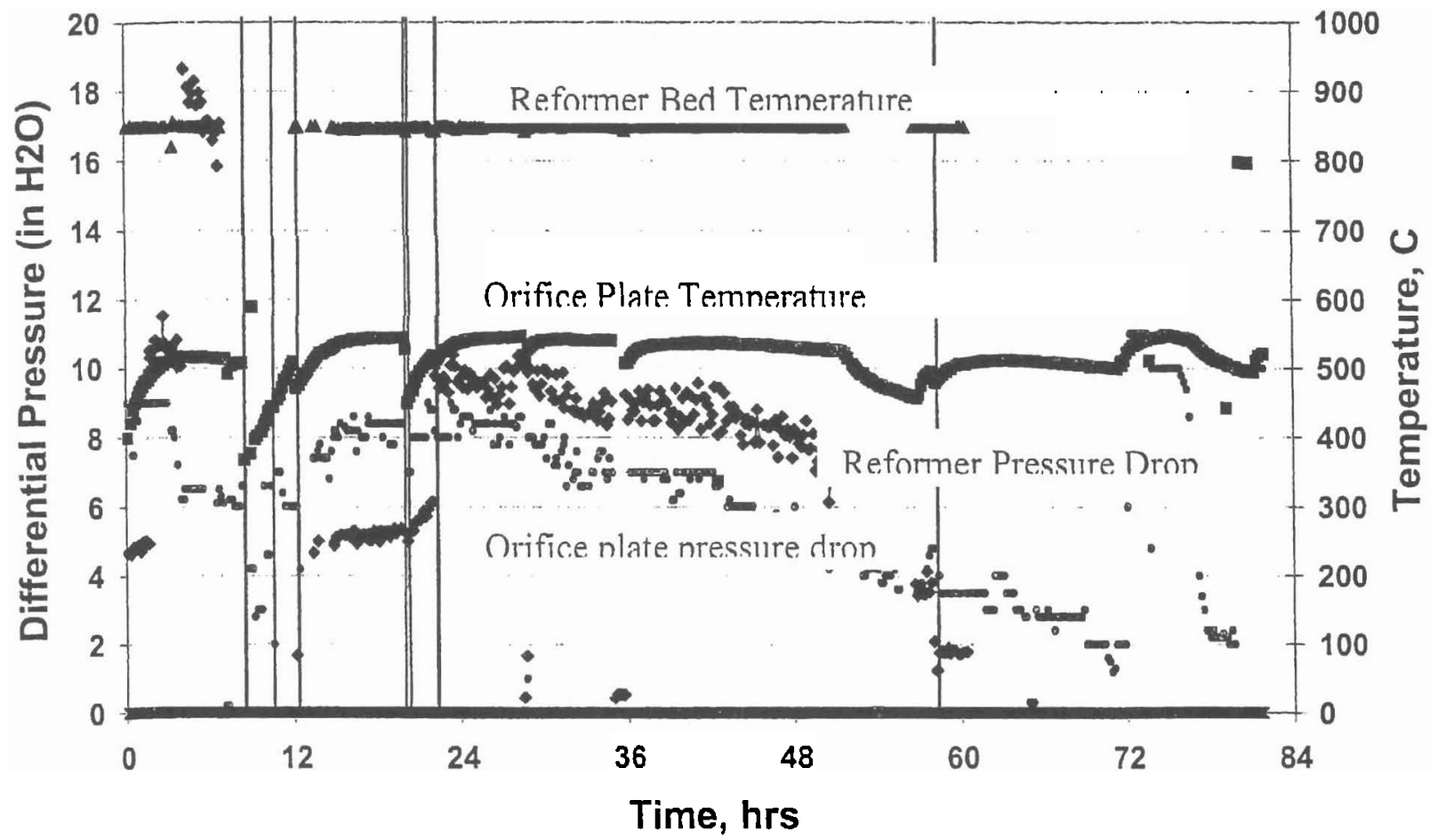

Figure 2. Temperature and pressure profiles of reformer and orifice plate

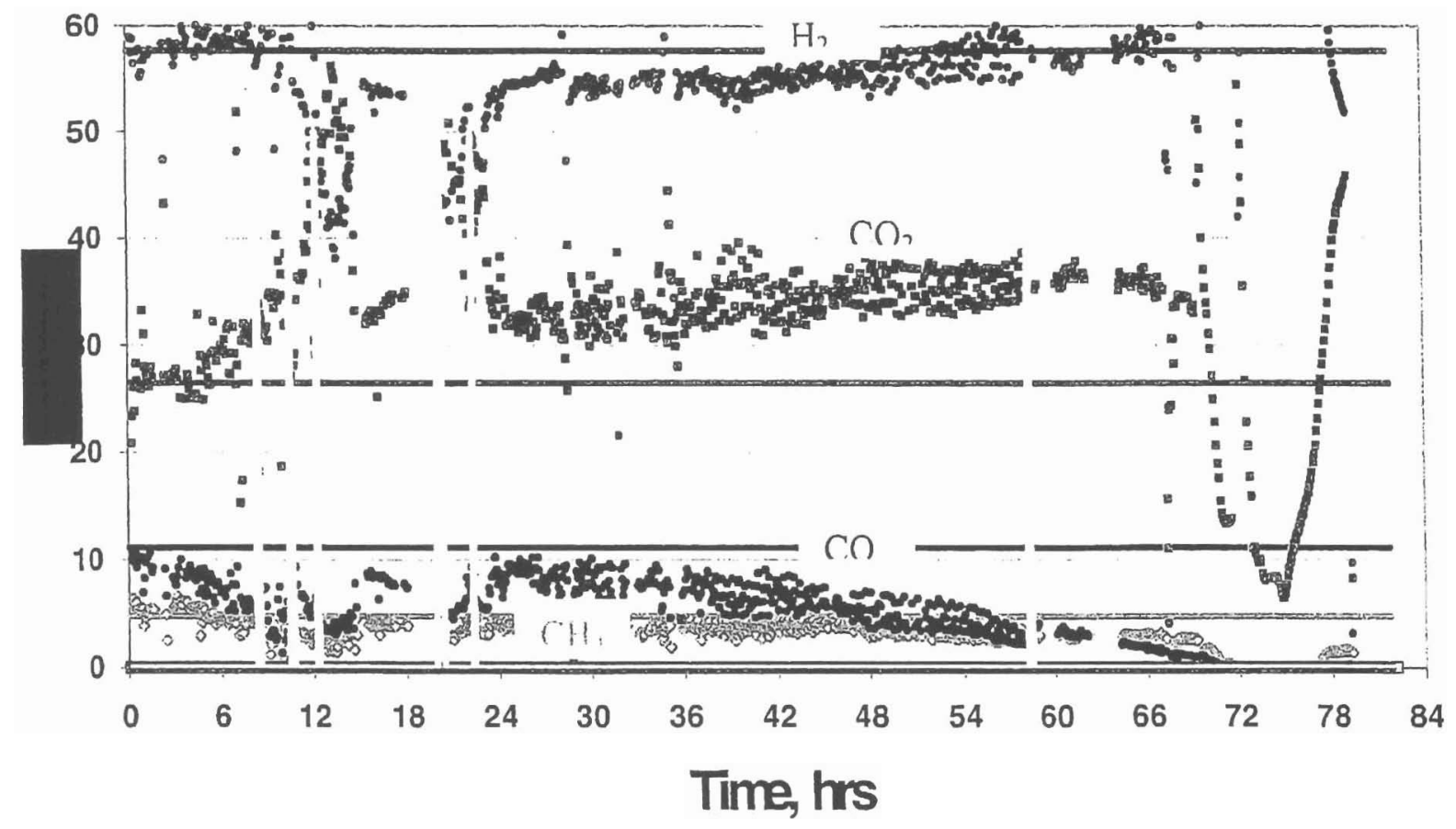

Figure 3. Composition profile of the reformer gas over the long-term run period 


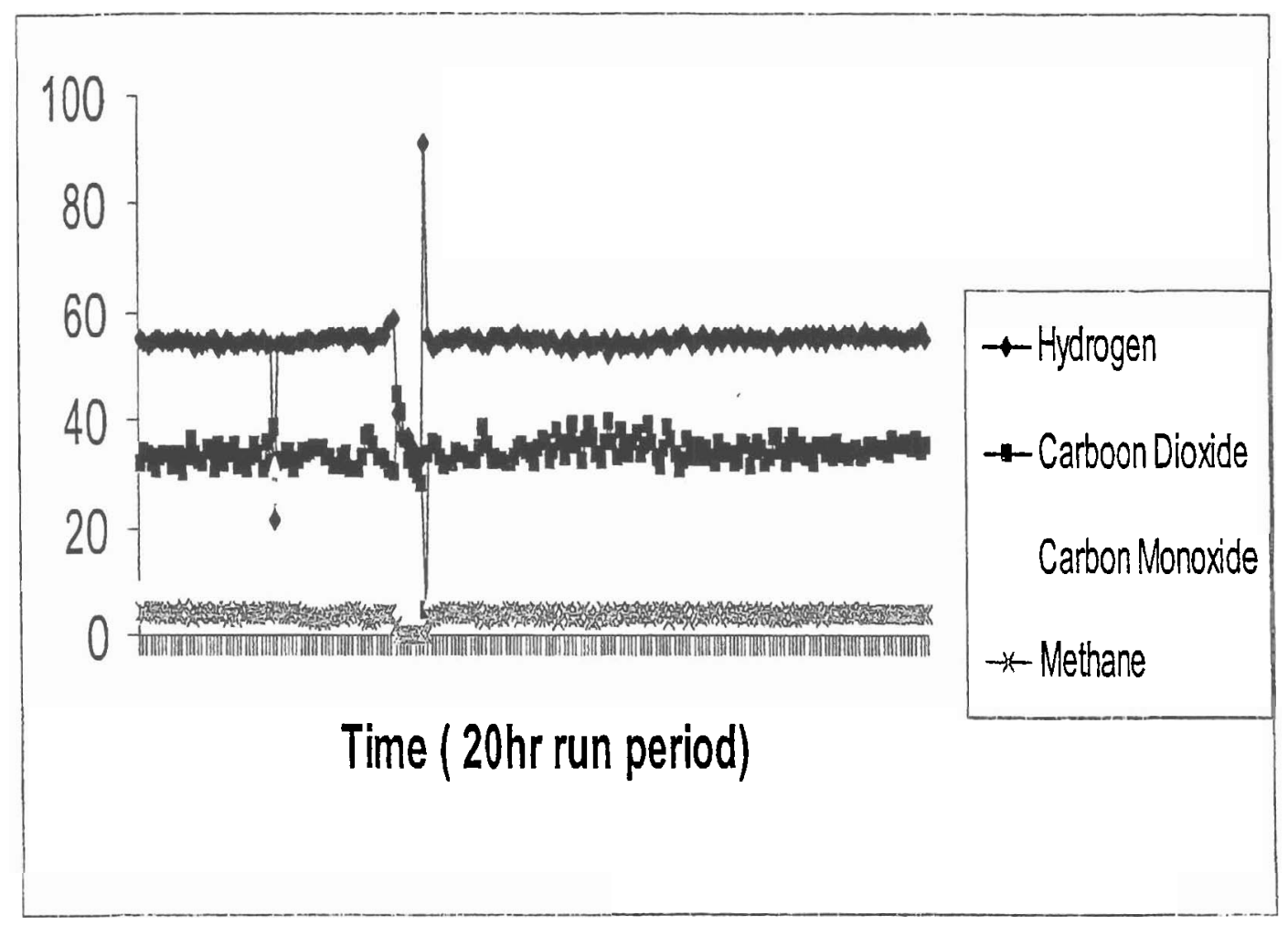

Figure 4. Gas composition over a 20 -hr period during the long-term catalyst testing

Table1. Yields and Gas Composition for the 100-hour run

Pyrolyzer (Yields \%)

Reformer Gas Product Composition, (\% Dry $\mathrm{N}_{2}$-free basis)

\begin{tabular}{lrlr}
\hline Char & $32 \%$ & Hydrogen & $57 \%$ \\
Water & $32 \%$ & Carbon Dioxide & $26 \%$ \\
Bio-Oils & $31 \%$ & Carbon Monoxide & $12 \%$ \\
Gases & $5 \%$ & Methane & $5 \%$
\end{tabular}

Task 5: Environmental and technical evaluation

Among the specific analytical equipment acquired for monitoring the composition profiles were:

- Gas Chromatograph (GC)

- Hydrogen Analyzer

- Carbon Monoxide (CO) Analyzer

- Carbon Dioxide $\left(\mathrm{CO}_{2}\right)$ Analyzer

- Oxygen $\left(\mathrm{O}_{2}\right)$ Analyzer

- NOx Analyzer 
Sox Analyzer

- Total Unburned Hydrocarbon Analyzer

The hydrogen analyzer and the gas chromatograph were set up to continuously monitor on line the gas composition and the performance of the reformer bed.

Task 6: Partnership building and outreach

The project team initiated discussions with the University of Georgia (UGA) to move the pilot unit from Blakely, GA to the Bioconversion Center facilities at UGA. The idea was enthusiastically received by UGA. Several meetings were held among the project partners and UGA at Clark Atlanta University and UGA. The current plans are to move the unit to the Bioconversion Center Facilities in the summer of 2003. Among the many advantages of the move are:

- Proximity-The distance of UGA from the participating partners will promote more active participation by all team members in the pilot scale studies, particularly students from Clark Atlanta University, Georgia Tech and UGA.

- Technical Expertise- UGA with the expertise of its faculty and graduate and undergraduate students on bioconversion and agriculture would provide significant technical expertise especially in the utilization of co-products such as the char in a novel slow release fertilizer concept.

- Safety Concerns- The bioconversion center facilities provide the needed resources and expertise to enable the team to incorporate all safety measures in the implementation of Phase 3. Safety is a major concern in this project. A team of safety experts from NREL visited, together with the project team, the UGA facilities and agreed on the appropriateness of the Center for the proposed study. They also provided guidance and recommendations to address outstanding safety issues.

Synergy- UGA with its spacious Bioconversion Center Facilities and extensive research and expertise in agriculture provides a natural fit to enable the project to expand in the use of other biomass feedstocks and the identification of co-product options to ensure an economically viable process. Thus, the project can be expanded into a biomass refinery for hydrogen and bioproducts.

- Space and resources- The Bioconversion Center at UGA, completed in 1997, consists of about eight (8) acres of fenced and gated land in a rural setting located next to the University's White Hall 800 acres forest. The property is bounded by several hundred acres of pasture and forest, part of the University's agriculture research facilities. The bioconversion center has two main buildings with laboratories and pilot scale research equipment. The Center has a continuous flow of biomass brought to the site consisting of plant and tree trimmings from the main campus that are currently chipped and ground for the manufacture of compost accomplished in a full-scale composting facility on site. Thus, the facility is truly idea for the proposed study. 


\section{PROPOSED FUTURE WORK}

Among the on-going activities that will be continued and or completed are:

- Development of models and solutions

- Solubility and physical property measurements and estimations

- Extraction studies and the evaluation of phenolates as co-products for adhesives

- Process design and economics of process flowsheet

- Modifications in pyrolyzer, reformer, analysis and other existing process units

- Design, installation and testing of the preheater and PSA units

- Installation of new sensors and process control system software

- Shakedown of the integrated system

- Completion of the proposed 1000 hours of operation

- Completion of the engine tests for stationary applications

- Design, integration and testing of the analytical systems

- Review and evaluation of storage system

- Assess community views on risks and benefits

- Complete all partnership arrangements

\section{COOPERATIVE EFFORTS}

- The participating organizations have worked to establish the use of hydrogen from biomass or agricultural residues and the development of integrated bioprocessing as major regional thrusts in Georgia and the southeast. Many meetings were held with state and local governments to publicize the project and incorporate the approach in the economic development initiatives for the rural south.

- We have developed strategies for partnership building and information dissemination among interested local, regional and national parties.

- The evaluation of an integrated co-products process that utilizes various agricultural residues/feedstocks for enhanced economic benefits is in progress.

- This multifaceted project involving five organizations (Clark Atlanta University, Georgia Tech, Enviro-Tech, Scientific Carbons Inc and the National Renewable Energy Lab) in three states was successfully managed through frequent visits/meetings and conference calls among team members.

- Collaboration and cooperation among the related projects at NREL to establish the underlying science of the process were strengthened.

- Development of new partnerships and collaboration with the University of Georgia, the Southern Company, and other interested parties were initiated.

- Abstarcts were submitted for presentation at national and international conferences on hydrogen.

- A website has been developed for the flow of information among the partners and for dissemination of information to the scientific community. 


\section{STUDENT TRAINING AND EDUCATION}

- Through this project, students especially chemical, mechanical, and agricultural engineering students at Clark Atlanta University, Georgia Tech and the University of Georgia will be trained and educated on hydrogen.

The project increases the level of participation of underrepresented minorities and especially at Clark Atlanta University, a historically black college or university, and thereby, ensures diversification in the nations workforce.

- Several Atlanta metropolitan high school students, after reading about the project in the local newspaper (Atlanta Journal and Constitution), decided to conduct various research projects in the subject area. They were guided in their work by the project team.

\section{REFERENCES}

1. The Green Hydrogen Report: The 1995 Progress Report of the Secretary of Energy's Hydrogen Technical Advisory Panel, May 1995, DOE/GO-10095-179 DE95009213.

2. Wang, D., S. Czernik, D. Montané, M. Mann, and E. Chornet, 1997, I\&EC Research, 36, 1507-1518.

3. Wang, D., S. Czernik, and E. Chornet, 1998, "Production of Hydrogen from Biomass by Catalytic Steam Reforming of Fast Pyrolysis Oil", Energy\&Fue/s, 12, 19-24.

4. Mann, M.K. 1995. "Technical and economic analyses of hydrogen production via indirectly heated gasification and pyrolysis," in Proceedings of the 1995 Hydrogen Program Review, Vol. 1, NREL/CP-430-20036-Vol. 1, pp. 205-236.

5. Wang, D., D. Montané, E. Chornet, 1996, "Catalytic Steam Reforming of Biomass-Derived Oxygenates: Acetic Acid and Hydroxyacetaldehyde", J. Appl. Catal. A: General, 143, 245270.

6. Czernik, S., D. Wang, D. Montané, E. Chornet, 1997, "Catalytic Steam Reforming of Biomass-Derived Fractions from Pyrolysis Processes. Developments in Thermochemical Biomass Conversion", Eds. Bridgwater, A.V. and Boocock, D.G.B., Blackie Academic \& Professional, pp.672-686.

7. Evans, Robert, National Renewable Energy Lab, Golden, CO, personal communication. 
Hydrogen from Biomass for Urban Transportation

Semiannual Progress Report

Reporting Period Start Date: April 1, 2003

Report Period End Date: September 2003

Principal Authors: Y. D. Yeboah (PI), Z. Wang and K. B. Bota

Clark Atlanta University, Atlanta, GA 30314

Email: yyeboah@cau.edu; Phone: 404-880-6619

M. Realff

Georgia Institute of Technology, Atlanta, GA

D. Day and J. Howard

Scientific Carbons Inc, Blakely, GA

D. McGee

Enviro-Tech Enterprises Inc, Matthews, NC

R. Evans, E. Chornet, S. Czernik, C. Feik, R. French, S. Phillips, J. Patrick, L. Boyd and C. Elam

National Renewable Energy Lab, Golden, CO

Date Report Was Issued: October 2003

DOE Award Number: DE-FC36-00G010528

Submitted by: Clark Atlanta University, Atlanta, GA 30314

Eprida Scientific Carbons Inc., Atlanta, GA

Georgia Institute of Technology

Enviro-Tech Enterprises Inc. 


\title{
Hydrogen from Biomass for Urban Transportation
}

\author{
Y. D. Yeboah (Primary Contact), K. B. Bota, and Z. Wang \\ Clark Atlanta University \\ 223 James $P$. Brawley Drive \\ Atlanta, GA 30314 \\ 404-880-6619(Phone), 404-880-6615 (Fax), yyeboah@cau.edu
}

DOE Program Manager: Mr. Doug Hooker

303-275-4780(Phone), 303-275-4753 (fax), doug_hooker@nrel.gov

Technical Advisor: Dr. Robert Evans

303-384-6284 (Phone), 303-384-6363 (fax), bob_evans@nrel.gov

Golden Field Office, Golden, CO

Subcontractors:

Eprida Scientific Carbons Inc, Blakely, GA

Georgia Institute of Technology, Atlanta, GA

Enviro-Tech Enterprises Inc, Matthews, $N C$

\section{Introduction}

Biomass can be converted to hydrogen by two distinct strategies: 1) gasification followed by shift conversion and 2) pyrolysis of biomass to form a bio-oil that can be subsequently converted to hydrogen via catalytic steam reforming and shift conversion. The project uses the latter approach, which has the potential to be cost competitive with current commercial processes for hydrogen production [1]. The process has been demonstrated at the bench scale at the National Renewable Energy Lab (NREL) using model compounds and the carbohydrate-derived fraction of bio-oil $[2,3]$. The concept has several advantages over the traditional gasification technology. Bio-oil is easily transportable so the second step (steam reforming) can be carried out at a different location, close to the existing infrastructure for hydrogen use or distribution. The second advantage is the potential for production and recovery of higher-value co-products from bio-oil that could significantly impact the economics of the entire process.

The project focuses on the use of agricultural residues such as peanut shells to produce hydrogen for urban transportation using the pyrolysis-reforming technology. Specifically, a pilot-scale reactor on site at Scientific Carbons Inc., a small company in Blakely, Georgia, that produces activated carbon by pyrolysis of densified peanut shells, is being used to test the concept. The primary focus of Phases 1 and 2 of the project was to undertake the process development studies in the use of the large quantities of peanut shells produced in Georgia as feedstock for the proposed pyrolysis-steam reforming process. Phase 1 designed, constructed and tested the reformer unit. In Phase 2, Scientific Carbons' pilot-scale pyrolyzer, which has a feed rate of 50 $\mathrm{kg} /$ hour, was integrated with the reformer and used to perform a demonstration of the process to convert the off-gas of the peanut-shell carbonization process to hydrogen. The integrated pilot 
process was successfully tested for 100 hours. Phase 3 will make further modifications and perform a 1,000 hours long term performance testing of the catalyst and pilot system. The process could be modified and expanded to run a variety of other feedstocks and to make a range of alternative products.

\section{Objectives}

- Undertake the engineering research and pilot scale process development studies to economically produce hydrogen from biomass such as peanut shells

- Educate and train underrepresented minorities to enhance diversity in the nation's workforce in the energy area.

\section{Technical Barriers}

The Hydrogen, Fuel Cells and Infrastructure Technologies Multiyear Program Plan technical barriers this project addresses, under hydrogen production, include:

- F. Feedstock Cost and Availability

- G. Efficiency of Gasification, Pyrolysis and Reforming Technology

\section{Approach}

The approach used to conduct the study is based on six main tasks:

1. Feedstock supply, process economics, and deployment strategies (Modeling, extraction and property estimation): Literature data and thermodynamic models were employed to evaluate a large number of organic solvents for the extraction of phenol from aqueous bio-oils. Several good solvents were identified and extractions were carried out on bio-oil samples provided by NREL. Process models for feedstock supply and deployment strategies were developed.

2. Reactor modifications and shakedown: Modifications in the pyrolyzer and reformer were made and the entire system, including the pyrolyzer, reformer, and analytical instruments were integrated and tested. The pyrolyzer unit achieves its heat requirements through the use of a rich burning natural gas burner. A computer is used to track the temperature and pressure drops across the reactors.

3. Long term catalyst testing: The pilot unit was operated in Phase 2 for 100 hours for the long term catalyst testing. Phase 3 will operate the unit for 1,000 hours.

4. Hydrogen separation, storage and utilization: The effort in hydrogen separation is focused on the use of pressure swing adsorption (PSA) for the separation of the hydrogen from carbon dioxide. After the baghouse and condenser, the reformer gas will be dried and compressed before being sent to the PSA system. The current plans are to use an accumulator to store the hydrogen before sending it into an engine for performance testing. 
5. Environmental and technical evaluation: A hydrogen analyzer and a gas chromatograph were set up to continuously monitor on line the gas composition and the performance of the reformer bed.

6. Partnership building and outreach: The project team initiated discussions with the University of Georgia (UGA) to move the pilot unit from Blakely, GA to the Bioconversion Center facilities at UGA. The idea was enthusiastically received by UGA. Several meetings were held among the project partners and UGA at Clark Atlanta University and UGA. The current plans are to move the unit to the Bioconversion Center Facilities in the summer of 2004.

\section{Results}
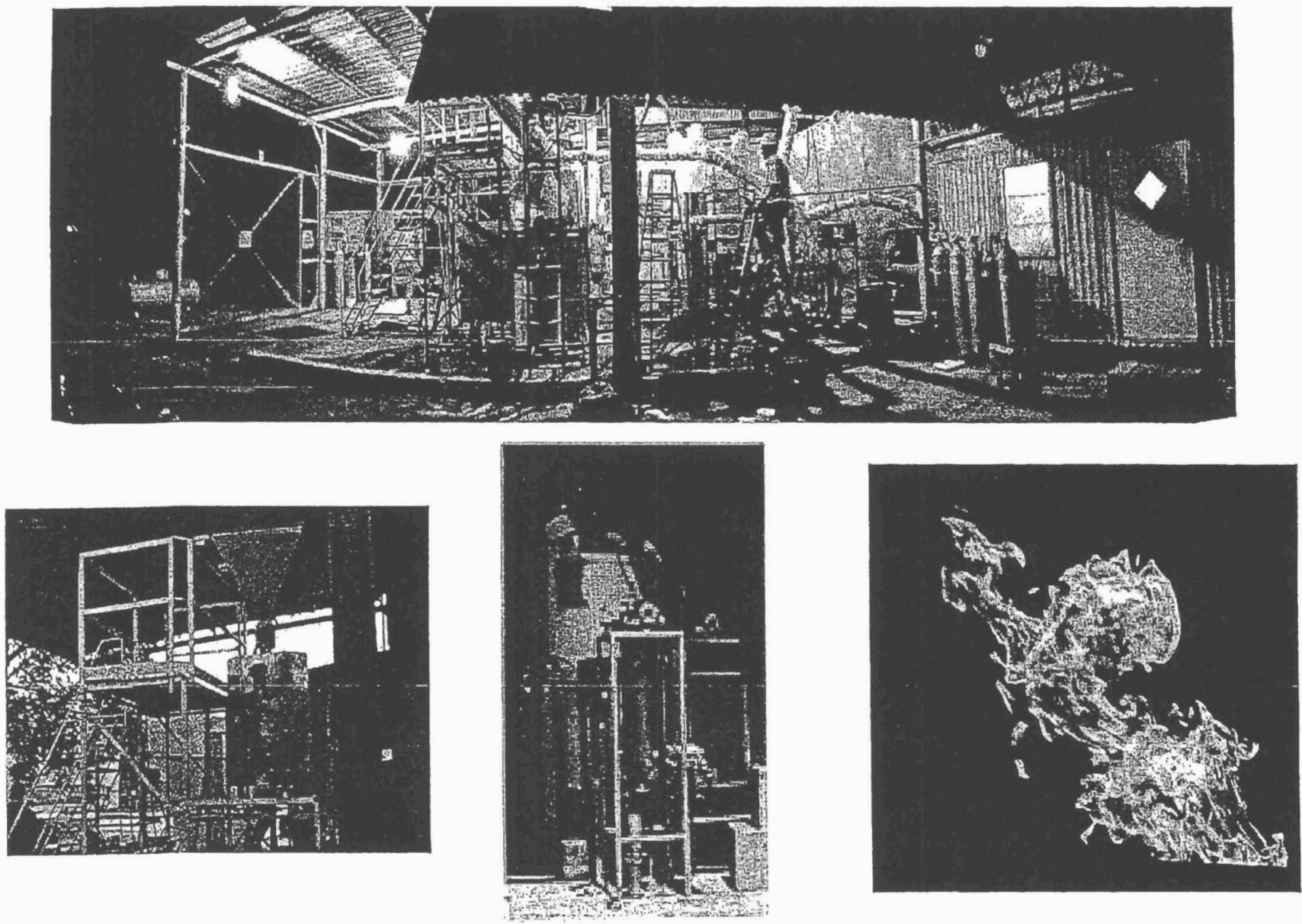

Figure 1 Pictures of the pilot plant unit, components and flares 


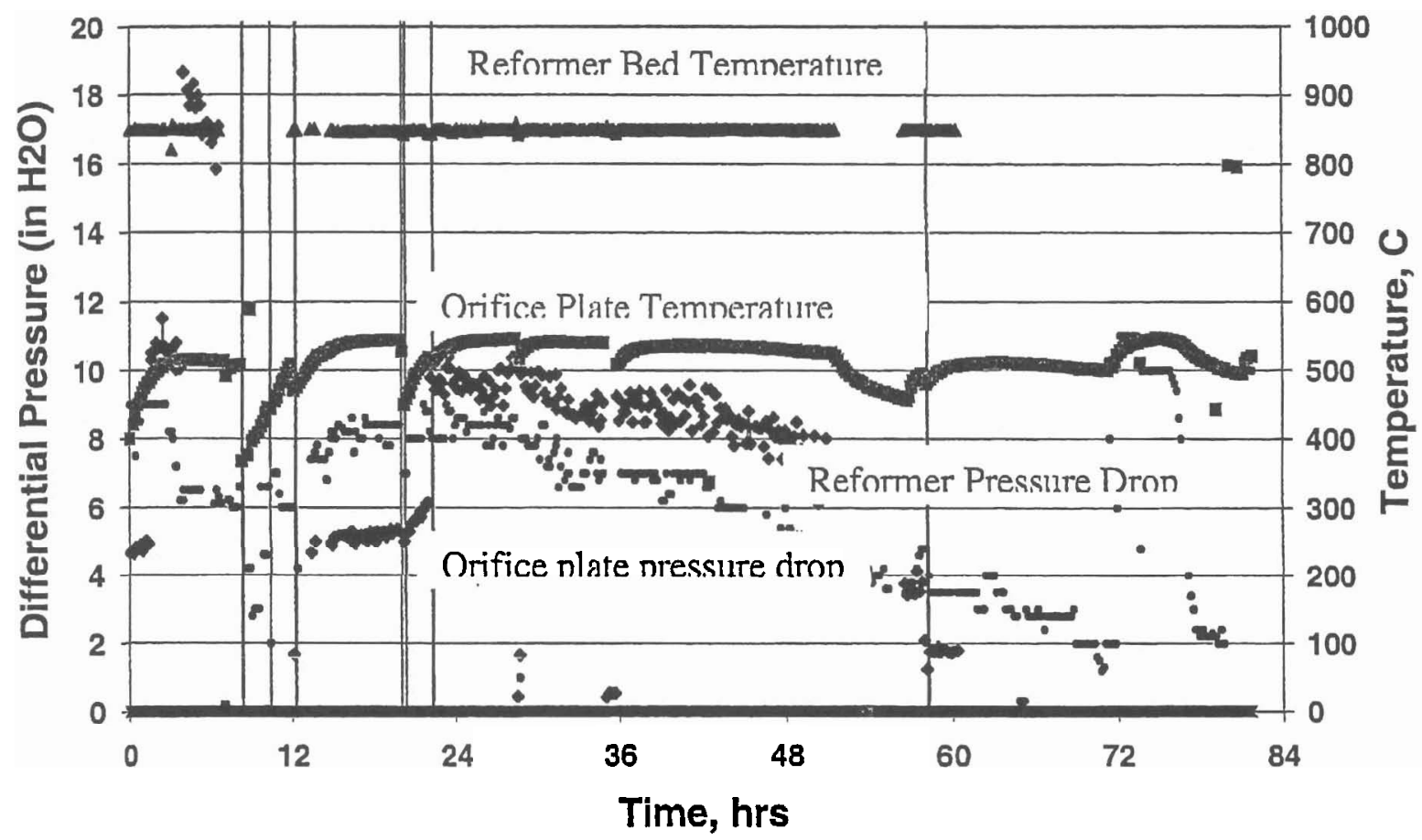

Figure 2. Temperature and pressure profiles of reformer and orifice plate

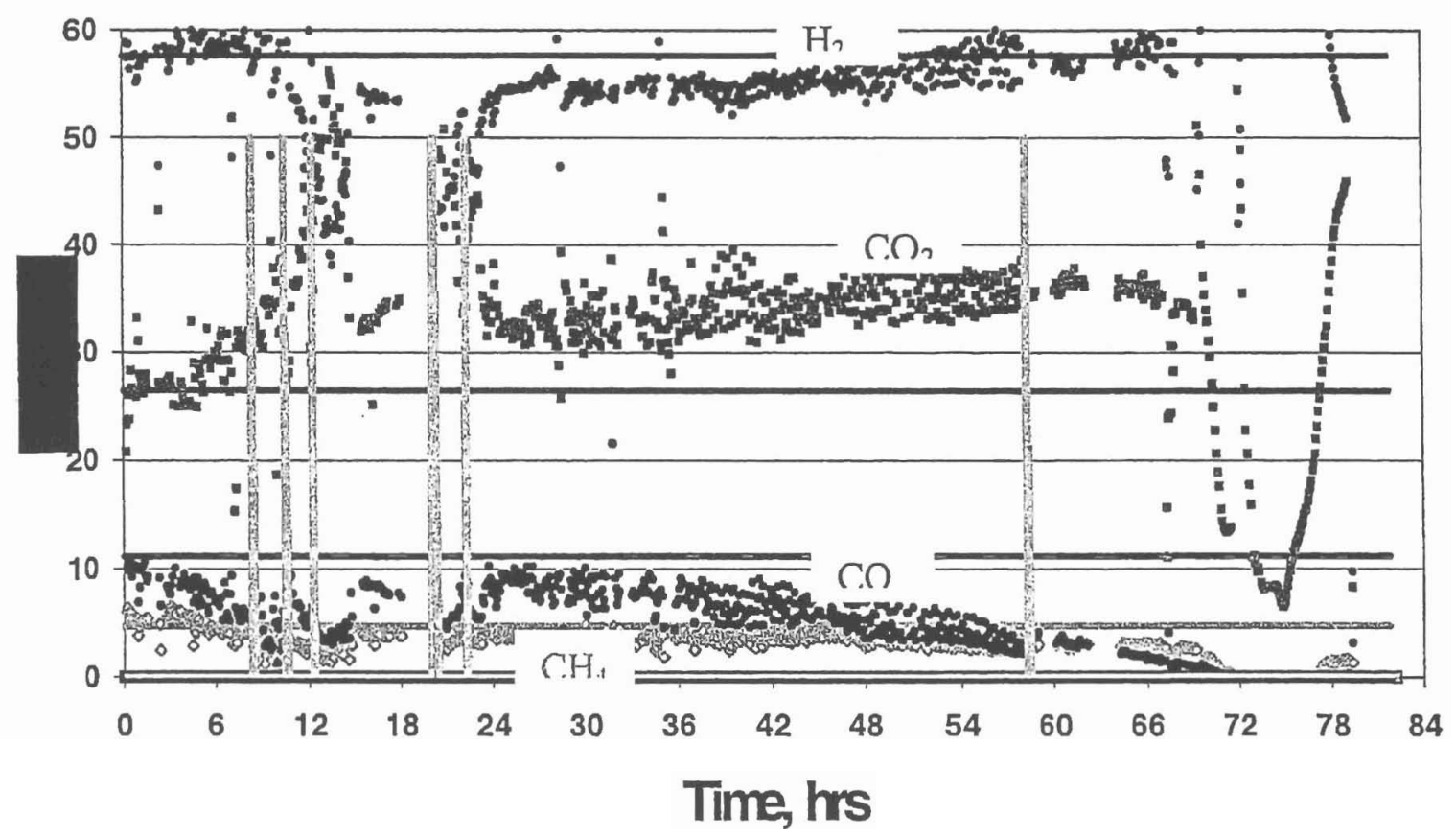

Figure 3. Composition profile of the reformer gas over the long-term run period 
Table1. Yields and Gas Composition for the 100-hour run

Pyrolyzer (Yields \%)

\begin{tabular}{lrlr}
\hline Char & 32 & Hydrogen & 57 \\
Water & 32 & Carbon Dioxide & 26 \\
Bio-Oils & 31 & Carbon Monoxide & 12 \\
Gases & 5 & Methane & 5
\end{tabular}

\section{Summary of Accomplishments}

- Continued developing a model of network of process steps to account for feedstock, location, process, and the uncertainties in these factors.

- Collected bio-oil and determined solubility parameters and physical property estimation methods of the components of the bio-oil product of peanut shell pyrolysis.

- Completed system modifications, integration and 100-hour pyrolysis-reformer run for long term catalyst testing of process

- Completed analysis of the data for the 100-hour long term catalyst testing

- Identified potential agricultural uses of the carbon product from the pyrolysis

- Developed plans for 1,000 hours long term testing of the catalyst and process for Phase 3

- Initiated partnership and collaboration with the University of Georgia, Athens, to move the pyrolysis-reformer pilot unit to their Bioconversion Center facilities in Athens, GA

- Initiated evaluation of approaches to hydrogen separation and storage including pressure swing adsorption (PSA) and Quantum's technology for hydrogen storage.

- Held Phase 3 project review meetings at Clark Atlanta University and the University of Georgia, Athens. All other communications among the project team were by conference calls.

- Prepared material for the Annual Hydrogen, Fuel Cells and Infrastructure Merit Review meeting in Berkeley, CA, held on May 18-22, 2003

\section{Conclusions}

- Demonstrated successfully pyrolysis-reformer concept for 100 hours operation

- Discovered agricultural uses and carbon sequestration strategy via novel carbon slow release sequestered fertilizer.

- Identified economical co-product options for bio-oils, e.g., adhesives.

- Run successfully the product gas in an engine with significant reduction of $\mathrm{NO}_{\mathrm{x}}$

- Further R \& D over 1,000 hours operation and higher hydrogen production rate could lead to economically competitive hydrogen and a viable integrated bioconversion process. 


\section{Future Directions}

- Complete development of models and solutions

- Perform solubility and physical property measurements and estimations

- Complete extraction studies and the evaluation of phenolates as co-products for adhesives

- Modify pyrolyzer, reformer, analysis and other process units for long term testing.

- Design, install and test preheater and PSA units

- Install new sensors and process control system software in pilot unit.

- Move and integrate units at the University of Georgia Bioconversion Center

- Perform shakedown run of the integrated system

- Complete the proposed 1,000 hours of long term operation

- Complete the engine tests for stationary applications

- Complete all partnership arrangements

\section{References}

1. Mann, M.K. 1995. "Technical and economic analyses of hydrogen production via indirectly heated gasification and pyrolysis," in Proceedings of the 1995 Hydrogen Program Review, Vol. 1, NREL/CP-430-20036-Vol. 1, pp. 205-236.

2. Wang, D., S. Czernik, D. Montané, M. Mann, and E. Chornet, 1997, I\&EC Research, 36, 1507-1518.

3. Wang, D., S. Czernik, and E. Chornet, 1998, "Production of Hydrogen from Biomass by Catalytic Steam Reforming of Fast Pyrolysis Oil", Energy\&Fuels, 12, 19-24. 
Hydrogen from Biomass for Urban Transportation

$$
\text { Semiannual Progress Report }
$$

Reporting Period Start Date: October 1, 2003

Report Period End Date: March 30, 2004

Principal Authors: Y. D. Yeboah (PI), Z. Wang and K. B. Bota

Clark Atlanta University, Atlanta, GA 30314

Email: yyeboah@cau.edu; Phone: 404-880-6619

\author{
M. Realff \\ Georgia Institute of Tethñology, Atlanta, GA \\ D. Day and J. Howard \\ Scientific Carbons Inc, Blakely, GA \\ D. McGee \\ Enviro-Tech Enterprises Inc, Matthews, NC \\ R. Evans, E. Chornet, S. Czernik, C. Feik, R. French, S. Phillips, J. Patrick, \\ L. Boyd and C. Elam \\ National Renewable Energy Lab, Golden, CO
}

Date Report Was Issued: April 2004

DOE Award Number: DE-FC36-00G010528

Submitted by: Clark Atlanta University, Atlanta, GA 30314

Eprida Scientific Carbons Inc., Atlanta, GA

Georgia Institute of Technology

Enviro-Tech Enterprises Inc. 


\section{Introduction}

Biomass can be converted to hydrogen by two distinct strategies: 1) gasification followed by shift conversion and 2) pyrolysis of biomass to form a bio-oil that can be subsequently converted to hydrogen via catalytic steam reforming and shift conversion. The project uses the latter approach, which has the potential to be cost competitive with current commercial processes for hydrogen production [1]. The process has been demonstrated at the bench scale at the National Renewable Energy Lab (NREL) using model compounds and the carbohydrate-derived fraction of bio-oil [2,3]. The concept has several advantages over the traditional gasification technology. Bio-oil is easily transportable so the second step (steam reforming) can be carried out at a different location, close to the existing infrastructure for hydrogen use or distribution. The second advantage is the potential for production and recovery of higher-value co-products from bio-oil that could significantly impact the economics of the entire process.

The project focuses on the use of agricultural residues such as peanut shells to produce hydrogen for urban transportation using the pyrolysis-reforming technology. Specifically, a pilot-scale reactor at Eprida Scientific Carbons Inc., a small company in Georgia, that produces activated carbon by pyrolysis of densified peanut shells, is being used to test the concept. The primary focus of Phases 1 and 2 of the project was to undertake the process development studies in the use of the large quantities of peanut shells produced in Georgia as feedstock for the proposed pyrolysis-steam reforming process. Phase 1 designed, constructed and tested the reformer unit. In Phase 2, Eprida Scientific Carbons' pilot-scale pyrolyzer, which has a feed rate of $50 \mathrm{~kg} /$ hour, was integrated with the Phase 1 reformer and used to perform a demonstration of the process to convert the off-gas of the peanut-shell carbonization process to hydrogen. The integrated pilot process was successfully tested for 100 hours. Phase 3 has made further modifications and is performing a 1,000-hour long-term performance testing of the catalyst and pilot system. The process could be modified and expanded to run a variety of other agricultural feedstocks and to make a range of alternative products.

\section{Objectives}

- Undertake the engineering research and pilot scale process development studies to economically produce hydrogen from biomass such as peanut shells

- Educate and train underrepresented minorities to enhance diversity in the nation's workforce in the energy area.

\section{Technical Barriers}

This hydrogen from biomass project addresses the following technical barriers from the 3.1.4.2.2 and 3.1.4.2.6 sections of the Hydrogen, Fuel Cells and Infrastructure Technologies Program Multiyear Research, Development and Demonstration Plan:

- F. Feedstock Cost and Availability

- G. Efficiency of Gasification, Pyrolysis, and Reforming Technologies

- Z. Catalysts

- AB. Hydrogen Separation and Purification

- AD. Market and Delivery 


\section{Approach}

The approach used to conduct the study is based on six main tasks:

1. Develop feedstock supply, process economics, and deployment strategies (Modeling, extraction and property estimation): Literature data and thermodynamic models were employed to evaluate a large number of organic solvents for the extraction of phenol from aqueous bio-oils. Several good solvents were identified and extractions were carried out on bio-oil samples provided by NREL. Process models for feedstock supply and deployment strategies were developed. The goal is to develop a process based on biomass pyrolysis and steam reforming of pyrolysis vapors (bio-oils and gases).

2. Design, construct, integrate and test pyrolysis-reformer pilot reaction unit including reactor modifications and shakedown. Modifications in the pyrolyzer and reformer were made and the entire system, including the pyrolyzer, reformer, and analytical instruments were integrated and tested. The pyrolyzer unit achieves its heat requirements through the use of a rich burning natural gas burner. A computer is used to track the temperature and pressure drops across the reactors. Pyrolysis conditions were $\mathrm{T}$ at $500^{\circ} \mathrm{C}$; P at $10 \mathrm{psig}$; and Feed Rate at $50-500 \mathrm{~kg} / \mathrm{hr}$ pelletized peanut shells. Gas and charcoal exited at about $425^{\circ} \mathrm{C}$.

3. Long term catalyst testing: The pilot unit was operated in Phase 2 for 100 hours for the long term catalyst testing and is being operated for 1000 hours in Phase 3. Reforming conditions were T: $850^{\circ} \mathrm{C} ; \mathrm{P}: 6 \mathrm{psig} ; \mathrm{H}_{2} \mathrm{O} / \mathrm{C}=5$, Catalyst: nickel-based (300-500 microns). The long term (1,000 hours) testing of the performance of the catalytic steam reforming in a fluidizedbed ( $25-250 \mathrm{~kg} /$ day $\mathrm{H}_{2}$ production) was undertaken.

4. Hydrogen separation, storage and utilization: The effort in hydrogen separation initially focused on the use of pressure swing adsorption (PSA) for the separation of the hydrogen from carbon dioxide. After the baghouse and condenser, the reformer gas was to be dried and compressed before being sent to the PSA system. The current plans are to send the reformer gasses directly into an engine for performance testing.

5. Environmental and technical evaluation: Develop an environmental and technical evaluation method based on engine tests and analytical monitoring of the process streams. A hydrogen analyzer and a gas chromatograph were set up to continuously monitor online the reformer gas composition and the performance of the reformer bed and the engine run.

6. Develop partnerships, collaborations and education and training programs through partnership building and outreach: The project team completed discussions with the University of Georgia (UGA) and moved the pilot unit from Blakely, GA to the UGA Bioconversion Center in Athens. All Phase 3 pilot experiments were conducted at the new facility in Athens, Georgia. 


\section{Results}
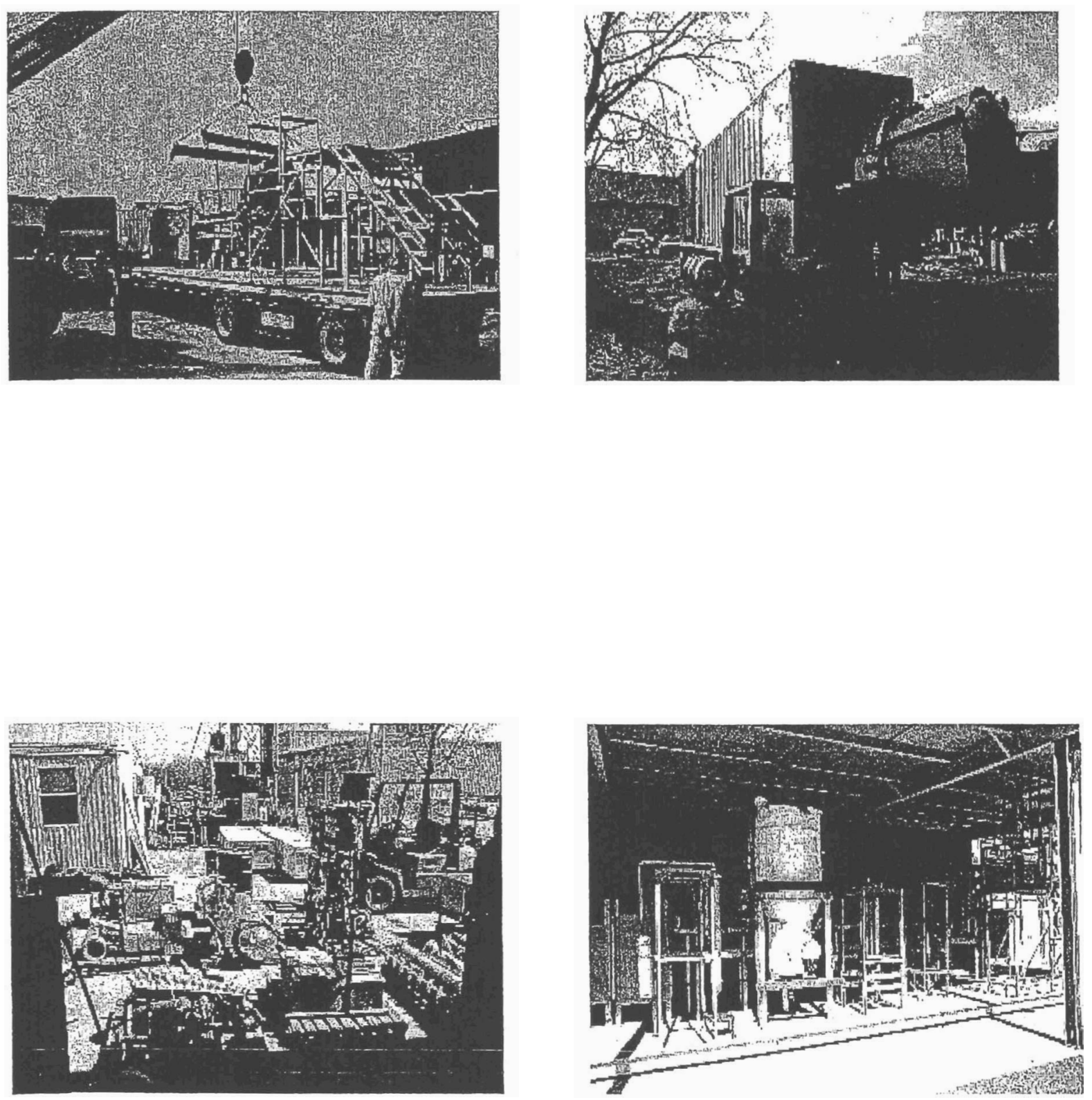

Figure 1. Pictures of the pilot plant unit being moved and reinstalled at Athens, GA 


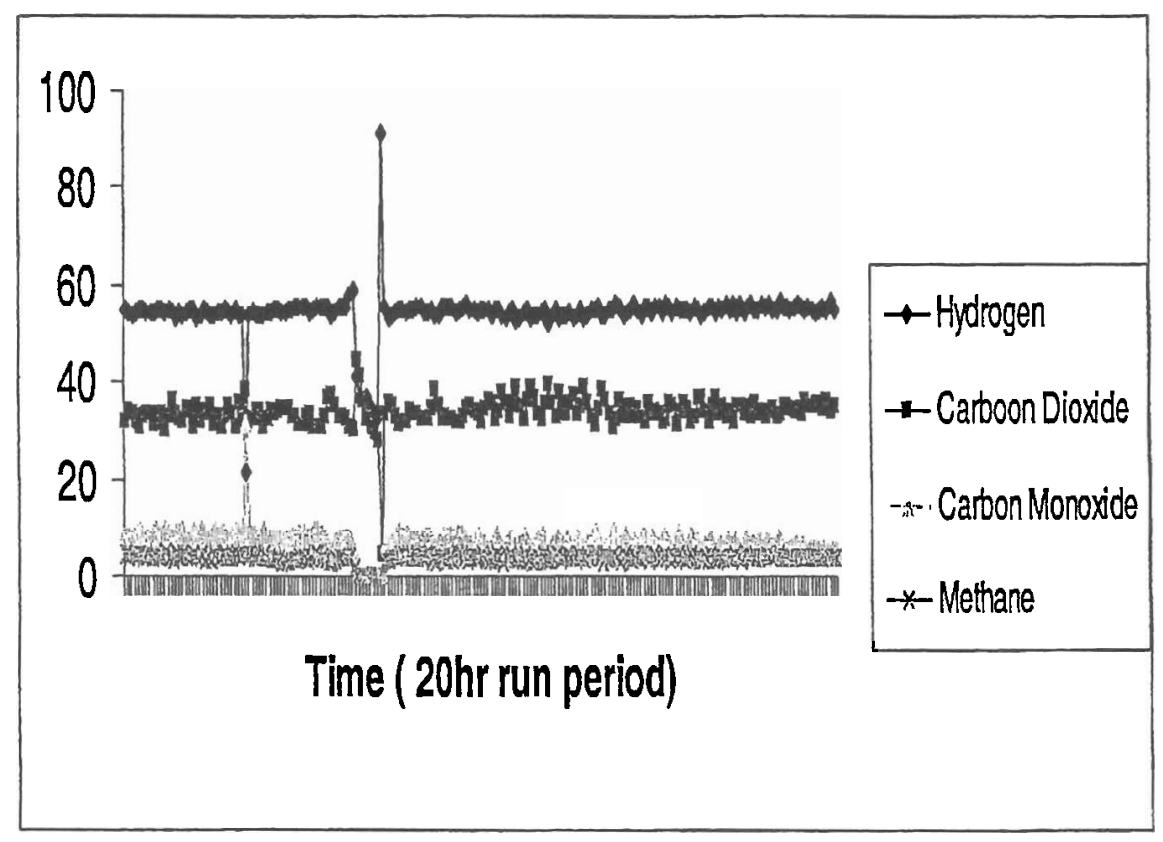

Figure 2. Typical gas composition over a 20-hr period during the long-term catalyst testing

Table1. Typical Yields and Gas Composition for the Pyrolysis and Reforming Pyrolyzer (Yields \%) Reformer Gas Product Composition (\% Dry $\mathrm{N}_{2}$-free basis)

\begin{tabular}{lrlr}
\hline Char & 32 & Hydrogen $\left(\mathrm{H}_{2}\right)$ & 57 \\
Water & 32 & Carbon Dioxide $\left(\mathrm{CO}_{2}\right)$ & 26 \\
Bio-Oils & 31 & Carbon Monoxide $(\mathrm{CO})$ & 12 \\
Gases & 5 & Methane $\left(\mathrm{CH}_{4}\right)$ & 5
\end{tabular}

\section{Summary of Accomplishments}

- Continued developing a model of network of process steps to account for feedstock, location, process, and the uncertainties in these factors.

- Completed design, construction and testing of reformer (Phase 1).

- Completed integration and 100 hours of successful operation of pyrolysis-reformer pilot unit (Phase 2).

- Completed analysis of the data for the 100-hour long term catalyst testing.

- Developed plans and completed modifications for the 1,000-hour long term testing of the catalyst and process for Phase 3.

- Currently completing the 1,000 -hour run pilot operation of the pilot unit. 
- Identified potential co-products options including agricultural uses of the carbon product from the pyrolysis.

- Developed partnerships and collaborations with potential companies and organizations including the University of Georgia (UGA), Athens. This resulted in the move of the pyrolysis-reformer pilot unit to UGA's Bioconversion Center in Athens, GA

- Initiated evaluation of approaches to hydrogen separation and storage including pressure swing adsorption (PSA) and Quantum's technology for hydrogen storage.

- Held Phase 3 project review meetings at Clark Atlanta University and the University of Georgia, Athens. All other communications among the project team were by conference calls.

- Educated and trained several underrepresented minorities on the project.

- Prepared material for the Annual Hydrogen, Fuel Cells and Infrastructure Merit Review meeting in Philadelphia, PA in May 2004.

\section{Future Directions}

- Complete development of models and solutions

- Complete extraction studies and the evaluation of phenolates as co-products for adhesives

- Complete and analyze the 1,000-hour long term study

- Complete the engine tests for stationary applications

- Complete all partnership arrangements

- Prepare a final report on the project.

\section{Conclusions}

- Demonstrated successfully pyrolysis-reformer concept for 100 hours operation in Phase 2

- Discovered agricultural uses and carbon sequestration strategy via novel carbon slow release sequestered fertilizer.

- Identified economical co-product options for bio-oils, e.g., adhesives.

- Run successfully the product gas in an engine with significant reduction of $\mathrm{NO}_{\mathbf{x}}$

- Currently in the middle of a successful demonstration of the pyrolysis-reformer concept in a 1000-hr operation during Phase 3.

Addition research and development work could lead to an economically competitive hydrogen and viable integrated bioconversion process.

\section{References}

1. Mann, M.K. 1995. "Technical and economic analyses of hydrogen production via indirectly heated gasification and pyrolysis," in Proceedings of the 1995 Hydrogen Program Review, Vol. 1, NREL/CP-430-20036-Vol. 1, pp. 205-236.

2. Wang, D., S. Czernik, D. Montané, M. Mann, and E. Chornet, 1997, I\&EC Research, 36, 1507-1518.

3. Wang, D., S. Czernik, and E. Chomet, 1998, "Production of Hydrogen from Biomass by Catalytic Steam Reforming of Fast Pyrolysis Oil", Energy \& Fuels, 12, 19-24. 
Hydrogen from Biomass for Urban Transportation

Annual Progress Report

Reporting Period Start Date: July 1, 2004

Report Period End Date: July 1, 2005

Principal Authors: K. B. Bota (PI), Z. Wang

Clark Atlanta University, Atlanta, GA 30314

Email: kbota@,cau.edu ; Phone: 404-880-6886

M. Realff

Georgia Institute of Technology, Atlanta, GA

D. Day and J. Howard

Scientific Carbons Inc, Blakely, GA

D. McGee

Enviro-Tech Enterprises Inc, Matthews, NC

R. Evans, E. Chornet, S. Czernik, C. Feik, R. French, S. Phillips, J. Patrick, L. Boyd and C. Elam

National Renewable Energy Lab, Golden, CO

Date Report Was Issued: July 2005

DOE Award Number: DE-FC36-00GO10528

Submitted by: Clark Atlanta University, Atlanta, GA 30314

Eprida Scientific Carbons Inc., Atlanta, GA

Georgia Institute of Technology

Enviro-Tech Enterprises Inc. 


\section{Introduction}

Biomass can be converted to hydrogen by two distinct strategies: 1) gasification followed by shift conversion and 2) pyrolysis of biomass to form a bio-oil that can be subsequently converted to hydrogen via catalytic steam reforming and shift conversion. This project uses the latter approach, which has the potential to be cost competitive with current commercial processes for hydrogen production [1]. The process was demonstrated at the bench scale at the National Renewable Energy Lab (NREL) using model compounds and the carbohydrate-derived fraction of bio-oil [2,3]. This approach has several advantages over the traditional gasification technology. Bio-oil is transportable, so the second step (steam reforming) can be carried out at a different location, close to the existing infrastructure for hydrogen use or distribution. The second advantage is the potential for production and recovery of higher-value co-products from bio-oil that could significantly impact the economics of the entire process.

The project has focused on the use of agricultural residues such as peanut shells to produce hydrogen for urban transportation using the pyrolysis-reforming technology. Specifically, a pilotscale reactor at Eprida Scientific Carbons Inc., a small company in Georgia, that produces activated carbon by pyrolysis of densified peanut shells, was initially used to test the concept. The primary focus of Phases 1 and 2 of the project was to undertake the process development studies in the use of the large quantities of peanut shells produced in Georgia as feedstock for the proposed pyrolysis-steam reforming process. Phase 1 designed, constructed and tested the reformer unit. In Phase 2, the pilot-scale pyrolyzer, which had a feed rate of $50 \mathrm{~kg} / \mathrm{hour}$, was integrated with the Phase 1 reformer and used to perform a demonstration of the process to convert the off-gas of the peanut-shell carbonization process to hydrogen. The integrated pilot process was successfully tested for 100 hours. In Phase 3 further modifications were made to allow a 1,000-hour long-term performance testing of the catalyst and pilot system. The process could be modified and expanded to run a variety of other agricultural feedstocks and to make a range of alternative products.

\section{Objectives}

- Undertake the engineering research and pilot scale process development studies to economically produce hydrogen from biomass such as peanut shells

\section{Technical Barriers}

This project addresses the following technical barriers from the 3.1.4.2.2 and 3.1.4.2.6 sections of the Hydrogen, Fuel Cells and Infrastructure Technologies Program Multiyear Research, Development and Demonstration Plan:

- F. Feedstock Cost and Availability

- G. Efficiency of Gasification, Pyrolysis, and Reforming Technologies

- Z. Catalysts

- AB. Hydrogen Separation and Purification

- $\mathrm{AD}$. Market and Delivery 


\section{Approach}

The approach used to conduct the study is based on six main tasks:

1. Develop feedstock supply, process economics, and deployment strategies (modeling, extraction and property estimation): Literature data and thermodynamic models were employed to evaluate a large number of organic solvents for the extraction of phenol from aqueous bio-oils. Several good solvents were identified and extractions were carried out on bio-oil samples provided by NREL. Process models for feedstock supply and deployment strategies were developed.

2. Design, construct, integrate and test pyrolysis-reformer pilot reaction unit including reactor modifications and shakedown: Modifications in the pyrolyzer and reformer were made and the entire system, including the pyrolyzer, reformer, and analytical instruments were integrated and tested. The pyrolyzer unit achieves its heat requirements through the use of a rich buming natural gas burner. A computer is used to track the temperature and pressure drops across the reactors. Pyrolysis conditions were $\mathrm{T}$ at $500^{\circ} \mathrm{C} ; \mathrm{P}$ at $10 \mathrm{psig}$; and Feed Rate at $50-500 \mathrm{~kg} / \mathrm{hr}$ pelletized peanut shells. Gas and charcoal exited at about $425^{\circ} \mathrm{C}$.

3. Long term catalyst testing: The pilot unit was operated in Phase 2 for 100 hours for the long term catalyst testing and is being operated for 1000 hours in Phase 3 . Reforming conditions were $\mathrm{T}: 850^{\circ} \mathrm{C} ; \mathrm{P}: 6$ psig; $\mathrm{H}_{2} \mathrm{O} / \mathrm{C}=5$, Catalyst: nickel-based (300-500 microns). The long term (1,000 hours) testing of the performance of the catalytic steam reforming in a fluidizedbed $\left(25-250 \mathrm{~kg} /\right.$ day $\mathrm{H}_{2}$ production) was undertaken.

4. Hydrogen separation, storage and utilization: The effort in hydrogen separation initially focused on the use of pressure swing adsorption (PSA) for the separation of the hydrogen from carbon dioxide. After the baghouse and condenser, the reformer gas was to be dried and compressed before being sent to the PSA system. The current design sends the reformer gases directly into an engine for performance testing.

5. Environmental and technical evaluation: Develop an environmental and technical evaluation method based on engine tests and analytical monitoring of the process streams. A hydrogen analyzer and a gas chromatograph were set up to continuously monitor online the reformer gas composition and the performance of the reformer bed and the engine run.

6. Develop partnerships, collaborations and education and training programs through partnership building and outreach: The project team completed discussions with the University of Georgia (UGA) and moved the pilot unit from Blakely, GA to the UGA Bioconversion Center in Athens. The Phase 3 experiments were done at the new facility in Athens, Georgia. 


\section{Results}

This project combined two stages: pyrolysis of biomass to generate bio-oil and catalytic steam reforming of the bio-oil to hydrogen and carbon dioxide. Figure 1 shows the schematic flow diagram of the process, which leads to the production of hydrogen and co-product charcoal.

The flow procedure of the process is: Feeder accepts biomass; the pyrolysis unit pyrolyzes the biomass into pyrolysis gas, bio-oil and char with a temperature around $450{ }^{\circ} \mathrm{C}$; char is led out at this stage; before the gas and bio-oil are introduced into catalytic reformer, they are heated to $680^{\circ} \mathrm{C}$; in the reformer at temperature $850^{\circ} \mathrm{C}$, most of pyrolysis gas is converted to hydrogen, carbon dioxide and water; after condensation and cooling down the water vapor, a mixture of hydrogen and carbon dioxide, along with nitrogen and other gases at normal temperature is produced. Hydrogen can be purified from this mixture by PSA system, then stored and used for engines or other application. In our experiments, hydrogen was burned at the exit.

The major components of the pilot scale plant include the feeder, superheater, pyrolyzer, filter, vapor heater, catalytic reformer, baghouse, condenser and dryer. The feeder accepts the feedstock (pelletized peanut shell) at a rate of $25-35 \mathrm{~kg}$ /hour. The superheater supplies water steam to the pyrolyzer at a rate of $15-25 \mathrm{~kg}$ /hour. The temperature and pressure of inside the pyrolyzer are maintained at $450{ }^{\circ} \mathrm{C}$ and $7 \mathrm{psi}$, respectively. In the pyrolyzer, the biomass was pyrolyzed into charcoal and pyrolysis gas. The baghouse acted as a filter. The vapor heater heats up the pyrolysis gas from $450 \mathrm{C}$ to $680 \mathrm{C}$ to prepare the gas to get into the reformer.

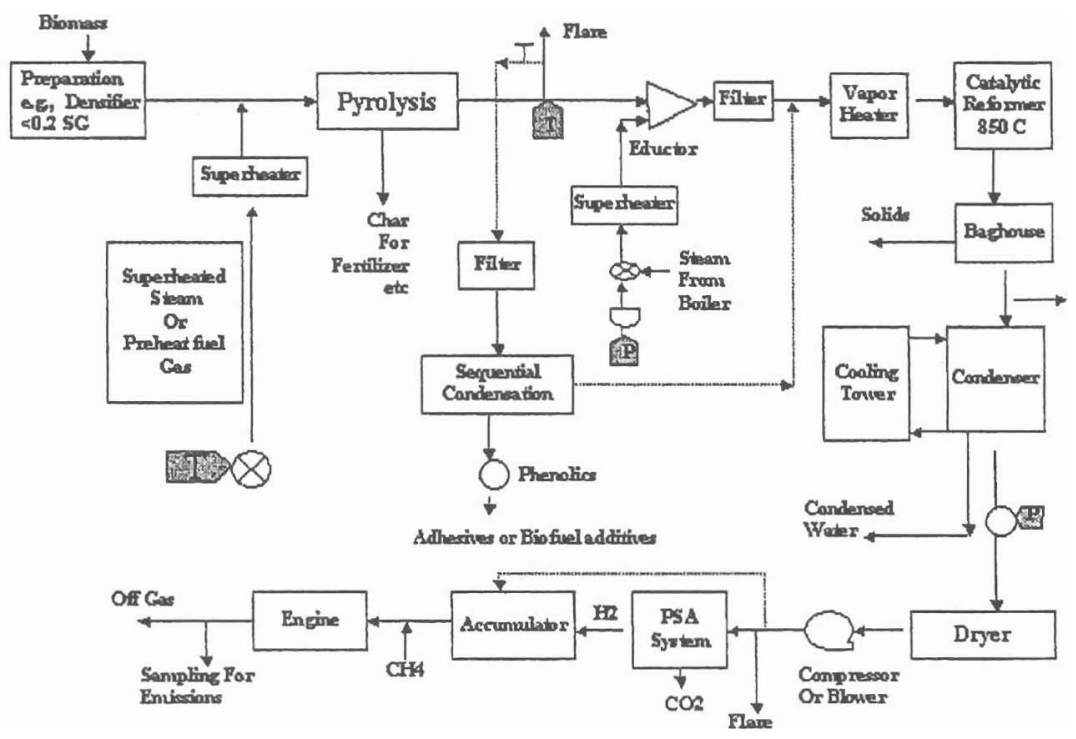

Figure 1. Schematic flow diagram of the biomass pyrolysis-reformer process.

A photograph of the pilot scale hydrogen production plant from biomass via integrated pyrolysis and fluidized catalytic reforming is shown in Figure 2. 


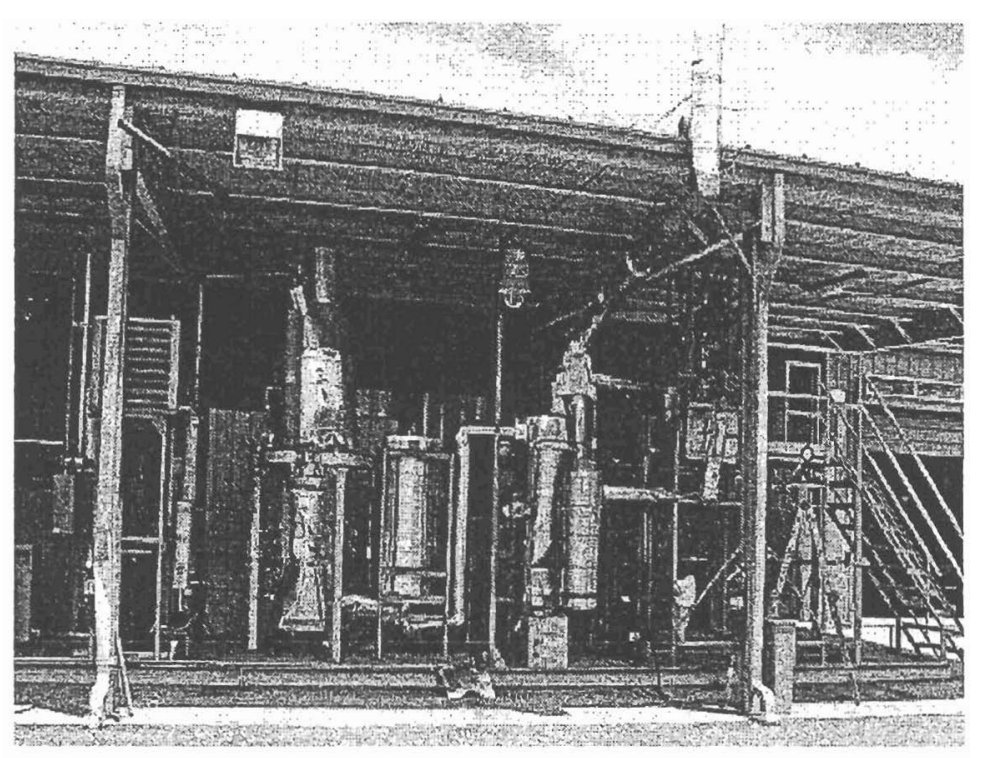

Figure 2. Photo of pilot scale hydrogen production plant from biomass

\section{Results and Discussion}

Pelleted peanut shell was used as the biomasss feedstock. Its composition is listed in Table 1.

Table 1 Typical analysis of peanut shell feedstock

\begin{tabular}{|c|c|}
\hline Compounds & Components (\%) \\
\hline Lignin & 34.8 \\
\hline Glucan & 21.1 \\
\hline Extractives & 14.2 \\
\hline Protein & 11.1 \\
\hline Xylan & 7.9 \\
\hline Ash & 3.4 \\
\hline Arabinan & 0.7 \\
\hline Galactan & 0.2 \\
\hline Mannan & 0.1 \\
\hline $\begin{array}{c}\text { Others (e.g., free } \\
\text { carbohydrates) }\end{array}$ & 0.5 \\
\hline
\end{tabular}

More than 100 hours operation has been run for this plant. Figure 3 is the temperature and pressure graph of the catalytic reformer during a 100 hours operation. At the normal operation, the reformer differential pressure was about $9 \mathrm{inH}_{2} \mathrm{O}$ and the temperature of reformer bed stayed constant at around $850^{\circ} \mathrm{C}$ 


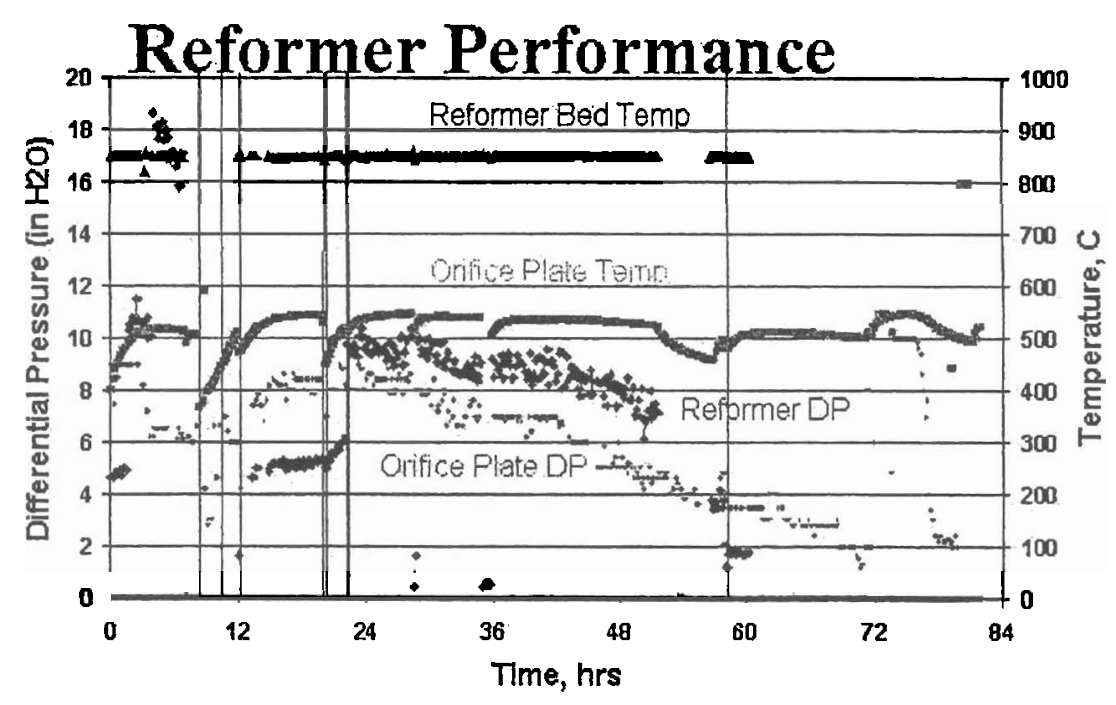

Figure 3. Reformer performance

The outcome of the pyrolysis process is shown in the Table 2. It includes $32 \mathrm{wt} \%$ activated carbon and $32 \mathrm{wt} \%$ water, $31 \mathrm{wt} \%$ bio-oil and $5 \mathrm{wt} \%$ gases. Bio-oil and gases can subsequently be converted into hydrogen.

Table 2. Typical product composition/yields

\begin{tabular}{|l|l|}
\hline Pyrolyzer (Yields) & $\%$ \\
\hline Char & 32 \\
\hline Water & 32 \\
\hline Bio-Oils & 31 \\
\hline Gases & 5 \\
\hline
\end{tabular}

Figure 4 is the plot of $\mathrm{N} 2$-free basis gas composition vs. time during 100 hours continuous run experiment and Figure 5 is the gas composition obtained during a 20 hours continuous stable run period. The nitrogen was input from outside to form the reforming fluidized bed. Most of the water steam was used to reform the bio-oil and gases into hydrogen; the remainder of the water is the reactant of the process. These figures show that $57 \%$ (at dry $\mathrm{N}_{2}-$ free basis) of hydrogen was obtained from the integration system. Meanwhile, the exit gas still included $31 \%$ carbon dioxide, $5 \%$ methane and $7 \%$ carbon monoxide. Thus, using peanut shells as feedstock, the overall yield from this system is up to $7 \mathrm{wt} \%$ hydrogen and $32 \mathrm{wt} \%$ charcoal/activated carbon. 


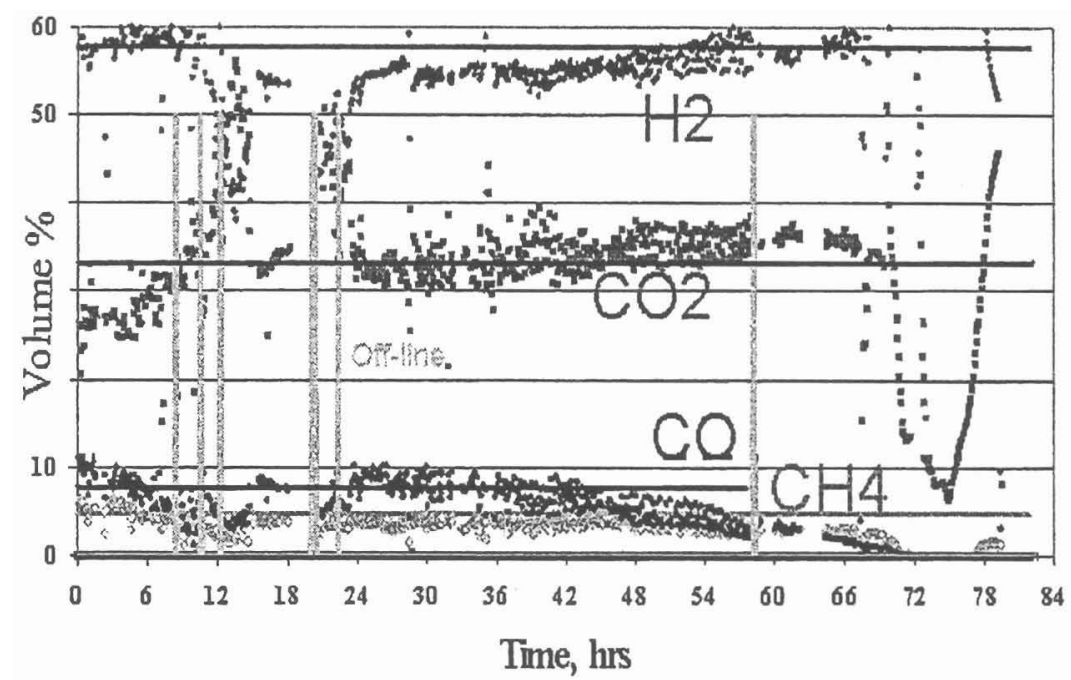

Figure 4. N2-free basis gas composition during 100 hours continuous run experiment

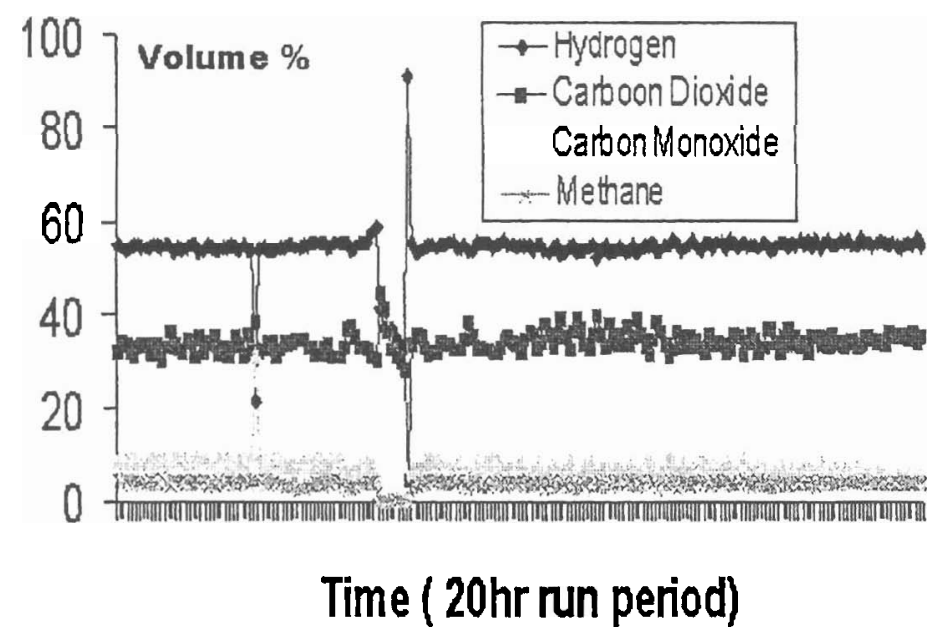

Figure 5, Dry N2-free basis gas composition during a stable run period

An assessment of the technical and economic potential of producing hydrogen from biomass has been made: first, the economics of different scales of feedstock and hydrogen production systems by examining the different options for producing intermediates at different scales and shipping them for further processing; second, modeling the separation of the different fractions of the bio-oil for enhancing their value; third, by modeling the mass and energy balances to enable an overall efficiency of the system to be calculated and to perform heat integration studies.

Capital costs were scaled from Mann's using 0.84 exponents. This exponent was derived from the three cases presented in the report. Fixed operating costs and working capital were also based on the report. Variable operating costs were estimated from the material balance. For a small facility of daily hydrogen production rate of 50 tons hydrogen, the total capital investment is $\$ 24$ million. The feedstock cost $\$ 16.5 / \mathrm{T}$ and operating cost is $\$ 5.9 /$ GJ. The overall yield from 
this process is $7 \mathrm{wt} \%$ hydrogen and $32 \mathrm{wt} \%$ charcoal/activated carbon of feedstock (peanut shell). The value of co-product activated carbon is $\$ 1.1 / \mathrm{GJ}$ and this co-product reduced the selling price of hydrogen. Thus the selling price of hydrogen is estimated to be $\$ 6.95 / \mathrm{GJ}$.

\section{Summary of Accomplishments}

During the 100-hours operation of experiment, $57 \%$ (at dry $\mathrm{N}_{2}$-free basis) of hydrogen was obtained from the integrated process, with the pyrolysis of biomass at $450^{\circ} \mathrm{C}$ and the reforming temperature of pyrolysis gas at $850^{\circ} \mathrm{C}$, respectively. Using peanut shells as feedstock, the overall yield from this process is up to $7 \mathrm{wt} \%$ hydrogen and $32 \mathrm{wt} \%$ charcoal/activated carbon. The preliminary techno-economic analysis indicates that this developed integrated process has the potential of producing hydrogen at the cost of about US\$7/GJ with an assumed facility of a daily hydrogen production rate of 50 tons.

We have successfully developed an integrated process of pyrolysis of biomass and reforming of the pyrolysis gas for hydrogen production at the pilot scale. The pilot scale plant we built for this process has increased the hydrogen production rate by orders of magnitude, while the yields of hydrogen at the pilot scale and the bench scale are comparable. The developed process shows the potential of being cost-competitive with those conventional means of hydrogen production.

In summary, this project has:

- Continued developing a model of network of process steps to account for feedstock, location, process, and the uncertainties in these factors.

- Completed integration and 100 hours of successful operation of pyrolysis-reformer pilot unit (Phase 2).

- Completed analysis of the data for the 100-hour long term catalyst testing.

- Developed plans and completed modifications for the 1,000-hour long term testing of the catalyst and process for Phase 3.

- Currently completing the 1,000 -hour run pilot operation of the pilot unit.

- Identified potential co-products options including agricultural uses of the carbon product from the pyrolysis.

- Conducted an analysis of the economic potential of producing hydrogen from biomass

- Developed partnerships and collaborations with potential companies and organizations including the University of Georgia (UGA), Athens. This resulted in the move of the pyrolysis-reformer pilot unit to UGA's Bioconversion Center in Athens, Georgia.

\section{Future Directions}

- Complete and analyze the 1,000-hour long term study

- Complete the engine tests for stationary applicat.

\section{References}

1. Mann, M.K. 1995. "Technical and economic analyses of hydrogen production via indirectly heated gasification and pyrolysis," in Proceedings of the 1995 Hydrogen Program Review, Vol. 1, NREL/CP-430-20036-Vol. 1, pp. 205-236.

2. Wang, D., S. Czernik, D. Montané, M. Mann, and E. Chornet, 1997, I\&EC Research, 36, $1507-1518$.

3. Wang, D., S. Czernik, and E. Chornet, 1998, "Production of Hydrogen from Biomass by Catalytic Steam Reforming of Fast Pyrolysis Oil", Energy \& Fuels, 12, 19-24. 


\title{
Eprida, Inc. \\ DOE/CAU/UGA Hydrogen from Biomass Project
}

Final Schedule of Eprida Activities

October 2005 - September 2007- Tasks and Objectives

Manpower

\author{
Danny Day \\ Robert Hawkins \\ Rebecca Oglesby \\ KC Das \\ Ryan Adolphson
}

\author{
Elaine Wilson \\ Jerry Owen \\ Donald Lakly
}

During the third quarter of 2006, Eprida's pilot plant at the University of Georgia bioconversion center was experiencing problems with clogging of the steam reformer distribution plate. The unit was operated biweekly, with the same results. Formation of carbon deposits on the distribution plate limited run time on the unit to an average of two to four hours before building pressures required shutdown of the system. Samples of the troublesome residue were analyzed to provide certainty that the material was carbon and not metal flakes from the piping. All other components of the pilot plant were operating as desired.

In the beginning of the fourth quarter of 2006, Calvin Feik from NREL was sent to Eprida's facilities by DOE to assist in solving the steam reformer distribution plate problems. $\mathrm{N}_{2}$ is used as a fluidizing gas until the pyrolytic reactor is ready to supply tars and steam. This gas is injected just prior to the gas pre-heater, which heats gasses to the reforming temperature of $850^{\circ} \mathrm{C}$. Calvin discovered that where this $\mathrm{N}_{2}$ was being injected, there was a cold spot being created that resulted in temperatures of the piping falling below the condensation point of the tars. Calvin designed a heating system for the reformer $\mathrm{N}_{2}$ supply that would heat the nitrogen to over $400^{\circ} \mathrm{C}$. Calvin also suggested a few operational techniques such as the best way to switch the reformer from fluidization with $\mathrm{N}_{2}$ to fluidization with pyrolysis vapors. With Calvin present, the unit was operated for 67 continuous hours. After Calvin's departure the GC measuring the unit off-gasses broke, and operation of the unit was postponed until the GC was operational. Hydrogen production runs resumed and the unit was in operation for 135 hours in the month of December.

During the first quarter of 2007, now that long, sustained runs on the pilot plant were possible, $100 \mathrm{hr}$. runs were targeted. Eprida's heat exchanger cracked in three places due to low ambient temperatures. Once this was repaired, $\mathrm{H}_{2}$ production runs were resumed. Now that the pilot plant was in operation for long periods of time, tests on the longevity of the catalyst were possible. It was noticed that after extended runtime on the catalyst, yellowish-white Naphthalene flakes were building up in the cooling unit gas filtration system and in the pipes leading to the flare from this system. It was also noted that the concentration of $\mathrm{C}_{2}$ gasses would increase in direct relationship with catalyst run-time. Eprida's pilot plant was in operation for $350 \mathrm{hrs}$ in this quarter.

In the second quarter of 2007, the pilot plant operation time was now limited by factors other than the pilot plant, such as the number of available workers. Most of the ball valve seals in Eprida's pilot plant require custom manufacturing by Eprida employees to withstand the temperatures required. Other routine maintenance such as filter replacement in the cooling unit and cleaning out of the baghouse was carried out in between runs. A one-cylinder gasoline generator was modified to accept the pilot plant's off gas by removing the gas tank and manufacturing a suitable carburetor. The performance of the generator running on the $\mathrm{H}_{2}$ rich syngas was higher than expected. Power outputs and efficiency calculations were made, and the efficiency was much higher on the pilot plant off gas than with gasoline. The pilot plant was in operation for 440 hours during this quarter. The total run time on the pilot plant since the project's initiation has now passed the $1000 \mathrm{hr}$ benchmark. 
$/ \|^{* \star *}$ THIS FILE IS FOR VIEWING ONLY! DO NOT EDIT THIS FILE! ***

IIU

// OptoDisplay Historical SuperTrend File Format

// Column 1: Pen ID

// Column 2: Date Stamp

// Column 3: Time Stamp

// Column 4: Scanned Value

// Pen 1: Eprida1:Float.H2 Flow

// Pen 2: Eprida1:Float.N2_Flow

// Pen 3: Eprida1:Float. $\mathrm{CH} 4$ Flow

// Pen 4: Eprida1:Float.CO_Flow

// Pen 5: Eprida1:Float.CO2_Flow

// Pen 6: Eprida1:Float.H2O Flow

6 03/10/2006 00:00:30.406 0.000000 5 03/10/2006 00:00:30.406 15.461699 4 03/10/2006 00:00:30.406 13.397500 3 03/10/2006 00:00:30.406 4.943170

2 03/10/2006 00:00:30.406 15.726100

1 03/10/2006 00:00:30.406 50.347198

6 03/10/2006 00:01:00.5150.000000

5 03/10/2006 00:01:00.515 15.461699

4 03/10/2006 00:01:00.515 13.397500

3 03/10/2006 00:01:00.515 4.943170

2 03/10/2006 00:01:00.515 15.726100

1 03/10/2006 00:01:00.515 50.347198

6 03/10/2006 00:01:32.500 0.000000

5 03/10/2006 00:01:32.500 15.461699

4 03/10/2006 00:01:32.500 13.397500

3 03/10/2006 00:01:32.500 4.943170

2 03/10/2006 00:01:32.500 15.726100

1 03/10/2006 00:01:32.500 50.347198

6 03/10/2006 00:02:02.3750.000000

5 03/10/2006 00:02:02.375 15.461699

4 03/10/2006 00:02:02.375 13.397500

\begin{tabular}{lrrrrrrr} 
Time & \multicolumn{3}{c}{$\mathrm{N}$} & \multicolumn{2}{c}{$\mathrm{CH}$} & $\mathrm{C}$ & $\mathrm{H} 2$ \\
12:00:30 AM & 50.3472 & 15.7261 & 4.94317 & 13.3975 & 15.4617 & 0 \\
12:01:01 AM & 50.3472 & 15.7261 & 4.94317 & 13.3975 & 15.4617 & 0 \\
12:01:33 AM & 50.3472 & 15.7261 & 4.94317 & 13.3975 & 15.4617 & 0 \\
12:02:02 AM & 50.3472 & 15.7261 & 4.94317 & 13.3975 & 15.4617 & 0 \\
12:02:33 AM & 50.3472 & 15.7261 & 4.94317 & 13.3975 & 15.4617 & 0 \\
12:03:06 AM & 50.3472 & 15.7261 & 4.94317 & 13.3975 & 15.4617 & 0 \\
12:03:39 AM & 50.3472 & 15.7261 & 4.94317 & 13.3975 & 15.4617 & 0 \\
12:04:06 AM & 50.3472 & 15.7261 & 4.94317 & 13.3975 & 15.4617 & 0 \\
12:04:37 AM & 50.3472 & 15.7261 & 4.94317 & 13.3975 & 15.4617 & 0 \\
12:05:10 AM & 47.633 & 15.8013 & 6.33731 & 0 & 15.0876 & 0 \\
12:05:42 AM & 47.633 & 15.8013 & 6.33731 & 0 & 15.0876 & 0 \\
12:06:10 AM & 47.633 & 15.8013 & 6.33731 & 0 & 15.0876 & 0 \\
12:06:43 AM & 47.633 & 15.8013 & 6.33731 & 0 & 15.0876 & 0 \\
12:07:13 AM & 47.633 & 15.8013 & 6.33731 & 0 & 15.0876 & 0 \\
12:07:45 AM & 47.633 & 15.8013 & 6.33731 & 0 & 15.0876 & 0 \\
12:08:15 AM & 47.633 & 15.8013 & 6.33731 & 0 & 15.0876 & 0 \\
12:08:45 AM & 47.9007 & 16.0769 & 6.38572 & 0 & 14.9932 & 0 \\
12:09:16 AM & 47.9007 & 16.0769 & 6.38572 & 0 & 14.9932 & 0 \\
12:09:50 AM & 47.9007 & 16.0769 & 6.38572 & 0 & 14.9932 & 0 \\
12:10:18 AM & 47.9007 & 16.0769 & 6.38572 & 0 & 14.9932 & 0 \\
12:10:50 AM & 47.9007 & 16.0769 & 6.38572 & 0 & 14.9932 & 0
\end{tabular}

SOURCE: CD-ROM 
3 03/10/2006 00:02:02.375 4.943170 2 03/10/2006 00:02:02.375 15.726100 1 03/10/2006 00:02:02.375 50.347198 6 03/10/2006 00:02:33.281 0.000000 5 03/10/2006 00:02:33.281 15.461699 4 03/10/2006 00:02:33.281 13.397500 3 03/10/2006 00:02:33.2814.943170 2 03/10/2006 00:02:33.281 15.726100 1 03/10/2006 00:02:33.281 50.347198 6 03/10/2006 00:03:06.203 0.000000 5 03/10/2006 00:03:06.203 15.461699 4 03/10/2006 00:03:06.203 13.397500 3 03/10/2006 00:03:06.203 4.943170 2 03/10/2006 00:03:06.203 15.726100 1 03/10/2006 00:03:06.203 50.347198 6 03/10/2006 00:03:38.937 0.000000 5 03/10/2006 00:03:38.937 15.461699 4 03/10/2006 00:03:38.937 13.397500 3 03/10/2006 00:03:38.937 4.943170 2 03/10/2006 00:03:38.937 15.726100 1 03/10/2006 00:03:38.93750.347198 6 03/10/2006 00:04:06.375 0.000000 5 03/10/2006 00:04:06.375 15.461699 4 03/10/2006 00:04:06.375 13.397500 3 03/10/2006 00:04:06.375 4.943170 2 03/10/2006 00:04:06.375 15.726100 1 03/10/2006 00:04:06.375 50.347198 6 03/10/2006 00:04:37.421 0.000000 5 03/10/2006 00:04:37.421 15.461699 4 03/10/2006 00:04:37.421 13.397500 3 03/10/2006 00:04:37.421 4.943170 2 03/10/2006 00:04:37.421 15.726100 1 03/10/2006 00:04:37.421 50.347198 6 03/10/2006 00:05:10.296 0.000000 5 03/10/2006 00:05:10.296 15.087600 4 03/10/2006 00:05:10.296 0.000000 3 03/10/2006 00:05:10.296 6.337310

$\begin{array}{llll}\text { 12:11:22 AM } & 47.9007 & 16.0769 & 6.38572 \\ \text { 12:11:54 AM } & 47.9007 & 16.0769 & 6.38572 \\ \text { 12:12:22 AM } & 47.9007 & 16.0769 & 6.38572 \\ \text { 12:12:54 AM } & 47.9007 & 16.0769 & 6.38572 \\ \text { 12:13:26 AM } & 47.9007 & 16.0769 & 6.38572 \\ \text { 12:13:56 AM } & 47.9007 & 16.0769 & 6.38572 \\ \text { 12:14:26 AM } & 47.9007 & 16.0769 & 6.38572 \\ \text { 12:14:57 AM } & 47.9007 & 16.0769 & 6.38572 \\ \text { 12:15:28 AM } & 47.9007 & 16.0769 & 6.38572 \\ \text { 12:16:01 AM } & 47.9007 & 16.0769 & 6.38572 \\ \text { 12:16:30 AM } & 47.9007 & 16.0769 & 6.38572 \\ \text { 12:17:02 AM } & 47.9007 & 16.0769 & 6.38572 \\ \text { 12:17:34 AM } & 47.9007 & 16.0769 & 6.38572 \\ \text { 12:18:06 AM } & 48.9924 & 16.5098 & 6.68965 \\ \text { 12:18:34 AM } & 48.9924 & 16.5098 & 6.68965 \\ \text { 12:19:05 AM } & 48.9924 & 16.5098 & 6.68965 \\ \text { 12:19:39 AM } & 48.9924 & 16.5098 & 6.68965 \\ \text { 12:20:09 AM } & 48.9924 & 16.5098 & 6.68965 \\ \text { 12:20:38 AM } & 48.9924 & 16.5098 & 6.68965 \\ \text { 12:21:09 AM } & 48.9924 & 16.5098 & 6.68965 \\ \text { 12:21:40 AM } & 50.0773 & 16.7432 & 6.83364 \\ \text { 12:22:14 AM } & 50.0773 & 16.7432 & 6.83364 \\ \text { 12:22:42 AM } & 50.0773 & 16.7432 & 6.83364 \\ \text { 12:23:14 AM } & 50.0773 & 16.7432 & 6.83364 \\ \text { 12:23:46 AM } & 50.0773 & 16.7432 & 6.83364 \\ \text { 12:24:19 AM } & 50.0773 & 16.7432 & 6.83364 \\ \text { 12:24:46 AM } & 50.0773 & 16.7432 & 6.83364 \\ \text { 12:25:18 AM } & 50.0773 & 16.7432 & 6.83364 \\ \text { 12:25:49 AM } & 50.0773 & 16.7432 & 6.83364 \\ \text { 12:26:20 AM } & 50.0773 & 16.7432 & 6.83364 \\ \text { 12:26:50 AM } & 50.0773 & 16.7432 & 6.83364 \\ \text { 12:27:22 AM } & 50.0773 & 16.7432 & 6.83364 \\ \text { 12:27:53 AM } & 50.0773 & 16.7432 & 6.83364 \\ \text { 12:28:25 AM } & 50.0773 & 16.7432 & 6.83364 \\ \text { 12:28:54 AM } & 50.0773 & 16.7432 & 6.83364 \\ \text { 12:29:26 AM } & 50.0773 & 16.7432 & 6.83364 \\ \text { 12:29:57 AM } & 50.0773 & 16.7432 & 6.83364\end{array}$

$\begin{array}{lll}0 & 14.9932 & 0 \\ 0 & 14.9932 & 0 \\ 0 & 14.9932 & 0 \\ 0 & 14.9932 & 0 \\ 0 & 14.9932 & 0 \\ 0 & 14.9932 & 0 \\ 0 & 14.9932 & 0 \\ 0 & 14.9932 & 0 \\ 0 & 14.9932 & 0 \\ 0 & 14.9932 & 0 \\ 0 & 14.9932 & 0 \\ 0 & 14.9932 & 0 \\ 0 & 14.9932 & 0 \\ 0 & 15.0781 & 0 \\ 0 & 15.0781 & 0 \\ 0 & 15.0781 & 0 \\ 0 & 15.0781 & 0 \\ 0 & 15.0781 & 0 \\ 0 & 15.0781 & 0 \\ 0 & 15.0781 & 0 \\ 0 & 15.1685 & 0 \\ 0 & 15.1685 & 0 \\ 0 & 15.1685 & 0 \\ 0 & 15.1685 & 0 \\ 0 & 15.1685 & 0 \\ 0 & 15.1685 & 0 \\ 0 & 15.1685 & 0 \\ 0 & 15.1685 & 0 \\ 0 & 15.1685 & 0 \\ 0 & 15.1685 & 0 \\ 0 & 15.1685 & 0 \\ 0 & 15.1685 & 0 \\ 0 & 15.1685 & 0 \\ 0 & 15.1685 & 0 \\ 0 & 15.1685 & 0 \\ 0 & 15.1685 & 0 \\ 0 & 15.1685 & 0\end{array}$


2 03/10/2006 00:05:10.296 15.801300 1 03/10/2006 00:05:10.296 47.633003 6 03/10/2006 00:05:42.437 0.000000 5 03/10/2006 00:05:42.437 15.087600 4 03/10/2006 00:05:42.4370.000000 3 03/10/2006 00:05:42.437 6.337310 2 03/10/2006 00:05:42.437 15.801300 1 03/10/2006 00:05:42.437 47.633003 6 03/10/2006 00:06:10.296 0.000000 5 03/10/2006 00:06:10.296 15.087600 4 03/10/2006 00:06:10.296 0.000000 3 03/10/2006 00:06:10.296 6.337310 2 03/10/2006 00:06:10.296 15.801300 1 03/10/2006 00:06:10.296 47.633003 6 03/10/2006 00:06:42.859 0.000000 5 03/10/2006 00:06:42.859 15.087600 4 03/10/2006 00:06:42.859 0.000000 3 03/10/2006 00:06:42.859 6.337310 2 03/10/2006 00:06:42.859 15.801300 1 03/10/2006 00:06:42.859 47.633003 6 03/10/2006 00:07:13.390 0.000000 5 03/10/2006 00:07:13.390 15.087600 4 03/10/2006 00:07:13.390 0.000000 3 03/10/2006 00:07:13.390 6.337310 2 03/10/2006 00:07:13.390 15.801300 1 03/10/2006 00:07:13.390 47.633003 6 03/10/2006 00:07:44.906 0.000000 5 03/10/2006 00:07:44.906 15.087600 4 03/10/2006 00:07:44.906 0.000000 3 03/10/2006 00:07:44.906 6.337310 2 03/10/2006 00:07:44.906 15.801300 1 03/10/2006 00:07:44.906 47.633003 6 03/10/2006 00:08:14.812 0.000000 5 03/10/2006 00:08:14.812 15.087600 4 03/10/2006 00:08:14.812 0.000000 3 03/10/2006 00:08:14.812 6.337310 2 03/10/2006 00:08:14.812 15.801300

\begin{tabular}{|c|c|c|c|c|c|}
\hline $12: 30: 29$ AM & 50.0773 & 16.7432 & 6.83364 & 0 & 15.1685 \\
\hline $12: 30: 58$ AM & 50.0773 & 16.7432 & 6.83364 & 0 & 15.1685 \\
\hline $12: 31: 30$ AM & 50.0773 & 16.7432 & 6.83364 & 0 & 15.1685 \\
\hline 12:32:01 AM & 49.9423 & 17.0996 & 6.96913 & 0 & 14.8357 \\
\hline 12:32:33 AM & 49.9423 & 17.0996 & 6.96913 & 0 & 14.8357 \\
\hline $12: 33: 02$ AM & 49.9423 & 17.0996 & 6.96913 & 0 & 14.8357 \\
\hline 12:33:33 AM & 49.9423 & 17.0996 & 6.96913 & 0 & 14.8357 \\
\hline $12: 34: 04$ AM & 49.9423 & 17.0996 & 6.96913 & 0 & 14.8357 \\
\hline $12: 34: 36$ AM & 49.9423 & 17.0996 & 6.96913 & 0 & 14.8357 \\
\hline $12: 35: 07$ AM & 49.9423 & 17.0996 & 6.96913 & 0 & 14.8357 \\
\hline $12: 35: 38$ AM & 50.1889 & 17.0334 & 6.91544 & 0 & 14.9693 \\
\hline $12: 36: 09$ AM & 50.1889 & 17.0334 & 6.91544 & 0 & 14.9693 \\
\hline $12: 36: 42$ AM & 50.1889 & 17.0334 & 6.91544 & 0 & 14.9693 \\
\hline $12: 37: 11 \mathrm{AM}$ & 50.1889 & 17.0334 & 6.91544 & 0 & 14.9693 \\
\hline $12: 37: 41 \mathrm{AM}$ & 50.1889 & 17.0334 & 6.91544 & 0 & 14.9693 \\
\hline 12:38:14 AM & 50.1889 & 17.0334 & 6.91544 & 0 & 14.9693 \\
\hline $12: 38: 44$ AM & 50.1889 & 17.0334 & 6.91544 & 0 & 14.9693 \\
\hline 12:39:14 AM & 50.1889 & 17.0334 & 6.91544 & 0 & 14.9693 \\
\hline $12: 39: 46$ AM & 50.1889 & 17.0334 & 6.91544 & 0 & 14.9693 \\
\hline 12:40:17 AM & 50.1889 & 17.0334 & 6.91544 & 0 & 14.9693 \\
\hline $12: 40: 49$ AM & 49.3331 & 16.7449 & 4.91264 & 12.9155 & 15.2256 \\
\hline $12: 41: 18$ AM & 49.3331 & 16.7449 & 4.91264 & 12.9155 & 15.2256 \\
\hline $12: 41: 50$ AM & 49.3331 & 16.7449 & 4.91264 & 12.9155 & 15.2256 \\
\hline $12: 42: 22$ AM & 49.3331 & 16.7449 & 4.91264 & 12.9155 & 15.2256 \\
\hline 12:42:53 AM & 49.3331 & 16.7449 & 4.91264 & 12.9155 & 15.2256 \\
\hline $12: 43: 22$ AM & 49.3331 & 16.7449 & 4.91264 & 12.9155 & 15.2256 \\
\hline $12: 43: 54$ AM & 49.3331 & 16.7449 & 4.91264 & 12.9155 & 15.2256 \\
\hline $12: 44: 26$ AM & 52.131 & 17.4337 & 0 & 9.77644 & 15.2933 \\
\hline $12: 44: 57 \mathrm{AM}$ & 52.131 & 17.4337 & 0 & 9.77644 & 15.2933 \\
\hline $12: 45: 26$ AM & 52.131 & 17.4337 & 0 & 9.77644 & 15.2933 \\
\hline $12: 45: 57 \mathrm{AM}$ & 52.131 & 17.4337 & 0 & 9.77644 & 15.2933 \\
\hline $12: 46: 30 \mathrm{AM}$ & 52.131 & 17.4337 & 0 & 9.77644 & 15.2933 \\
\hline 12:47:01 AM & 52.131 & 17.4337 & 0 & 9.77644 & 15.2933 \\
\hline $12: 47: 30 \mathrm{AM}$ & 52.131 & 17.4337 & 0 & 9.77644 & 15.2933 \\
\hline 12:48:01 AM & 52.131 & 17.4337 & 0 & 9.77644 & 15.2933 \\
\hline 12:48:33 AM & 52.131 & 17.4337 & 0 & 9.77644 & 15.2933 \\
\hline 12:49:05 AM & 52.131 & 17.4337 & 0 & 9.77644 & 15.2933 \\
\hline
\end{tabular}


1 03/10/2006 00:08:14.812 47.633003 6 03/10/2006 00:08:45.265 0.000000 5 03/10/2006 00:08:45.265 14.993199 4 03/10/2006 00:08:45.265 0.000000 3 03/10/2006 00:08:45.265 6.385720 2 03/10/2006 00:08:45.265 16.076900 1 03/10/2006 00:08:45.265 47.900700 6 03/10/2006 00:09:16.265 0.000000 5 03/10/2006 00:09:16.265 14.993199 4 03/10/2006 00:09:16.265 0.000000 3 03/10/2006 00:09:16.265 6.385720 2 03/10/2006 00:09:16.265 16.076900 1 03/10/2006 00:09:16.265 47.900700 6 03/10/2006 00:09:50.218 0.000000 5 03/10/2006 00:09:50.218 14.993199 4 03/10/2006 00:09:50.218 0.000000 3 03/10/2006 00:09:50.218 6.385720 2 03/10/2006 00:09:50.218 16.076900 1 03/10/2006 00:09:50.218 47.900700 6 03/10/2006 00:10:18.281 0.000000 5 03/10/2006 00:10:18.281 14.993199 4 03/10/2006 00:10:18.281 0.000000 3 03/10/2006 00:10:18.281 6.385720 2 03/10/2006 00:10:18.281 16.076900 1 03/10/2006 00:10:18.281 47.900700 6 03/10/2006 00:10:49.578 0.000000 5 03/10/2006 00:10:49.578 14.993199 4 03/10/2006 00:10:49.578 0.000000 3 03/10/2006 00:10:49.578 6.385720 2 03/10/2006 00:10:49.578 16.076900 1 03/10/2006 00:10:49.578 47.900700 6 03/10/2006 00:11:22.281 0.000000 5 03/10/2006 00:11:22.281 14.993199 4 03/10/2006 00:11:22.281 0.000000 3 03/10/2006 00:11:22.281 6.385720 2 03/10/2006 00:11:22.281 16.076900 1 03/10/2006 00:11:22.28147.900700

$\begin{array}{crr}12: 49: 34 \text { AM } & 52.131 & 17.4337 \\ 12: 50: 06 \text { AM } & 52.131 & 17.4337 \\ 12: 50: 38 \text { AM } & 52.5151 & 17.3515 \\ 12: 51: 10 \text { AM } & 52.5151 & 17.3515 \\ 12: 51: 38 \text { AM } & 52.5151 & 17.3515 \\ 12: 52: 10 \text { AM } & 52.5151 & 17.3515 \\ 12: 52: 40 \text { AM } & 52.5151 & 17.3515 \\ 12: 53: 12 \text { AM } & 52.5151 & 17.3515 \\ 12: 53: 42 \text { AM } & 52.5151 & 17.3515 \\ 12: 54: 13 \text { AM } & 53.531 & 17.6343 \\ 12: 54: 45 \text { AM } & 53.531 & 17.6343 \\ 12: 55: 18 \text { AM } & 53.531 & 17.6343 \\ 12: 55: 46 \text { AM } & 53.531 & 17.6343 \\ 12: 56: 18 \text { AM } & 53.531 & 17.6343 \\ 12: 56: 49 \text { AM } & 53.531 & 17.6343 \\ 12: 57: 22 \text { AM } & 53.531 & 17.6343 \\ 12: 57: 50 \text { AM } & 53.531 & 17.6343 \\ 12: 58: 21 \text { AM } & 53.531 & 17.6343 \\ 12: 58: 52 \text { AM } & 0 & 0 \\ 12: 59: 24 \text { AM } & 0 & 0 \\ 12: 59: 54 \text { AM } & 0 & 0 \\ 1: 00: 25 \text { AM } & 0 & 0 \\ 1: 00: 57 \text { AM } & 0 & 0 \\ 1: 01: 30 \text { AM } & 0 & 0 \\ 1: 01: 58 \text { AM } & 0 & 0 \\ 1: 02: 30 \text { AM } & 0 & 0 \\ 1: 03: 01 \text { AM } & 0 & 0 \\ 1: 03: 34 \text { AM } & 0 & 0 \\ 1: 04: 02 \text { AM } & 0 & 0 \\ 1: 04: 34 \text { AM } & 0 & 0 \\ 1: 05: 04 \text { AM } & 0 & 0 \\ 1: 05: 36 \text { AM } & 0 & 0 \\ 1: 06: 06 \text { AM } & 0 & 0 \\ 1: 06: 37 \text { AM } & 0 & 0 \\ 1: 07: 09 \text { AM } & 0 & 0 \\ 1: 07: 42 \text { AM } & 0 & 0 \\ 1: 08: 10 \text { AM } & 52.3627 & 17.431\end{array}$

0
0
0
0
0
0
0
0
0
0
0
0
0
0
0
0
0
0
0
0
0
0
0
0
0
0
0
0
0
0
0
0
0
0
0
0
0 
6 03/10/2006 00:11:54.500 0.000000 5 03/10/2006 00:11:54.500 14.993199 4 03/10/2006 00:11:54.500 0.000000 3 03/10/2006 00:11:54.500 6.385720 2 03/10/2006 00:11:54.500 16.076900 1 03/10/2006 00:11:54.500 47.900700 6 03/10/2006 00:12:22.218 0.000000 5 03/10/2006 00:12:22.218 14.993199 4 03/10/2006 00:12:22.218 0.000000 3 03/10/2006 00:12:22.218 6.385720 2 03/10/2006 00:12:22.218 16.076900 1 03/10/2006 00:12:22.218 47.900700 6 03/10/2006 00:12:54.375 0.000000 5 03/10/2006 00:12:54.375 14.993199 4 03/10/2006 00:12:54.375 0.000000 3 03/10/2006 00:12:54.375 6.385720 2 03/10/2006 00:12:54.375 16.076900 1 03/10/2006 00:12:54.375 47.900700 6 03/10/2006 00:13:26.468 0.000000 5 03/10/2006 00:13:26.468 14.993199 4 03/10/2006 00:13:26.468 0.000000 3 03/10/2006 00:13:26.468 6.385720 2 03/10/2006 00:13:26.468 16.076900 1 03/10/2006 00:13:26.468 47.900700 6 03/10/2006 00:13:56.3590.000000 5 03/10/2006 00:13:56.359 14.993199 4 03/10/2006 00:13:56.3590.000000 3 03/10/2006 00:13:56.359 6.385720 2 03/10/2006 00:13:56.359 16.076900 1 03/10/2006 00:13:56.359 47.900700 6 03/10/2006 00:14:26.218 0.000000 5 03/10/2006 00:14:26.218 14.993199 4 03/10/2006 00:14:26.218 0.000000 3 03/10/2006 00:14:26.218 6.385720 2 03/10/2006 00:14:26.218 16.076900 1 03/10/2006 00:14:26.218 47.900700 6 03/10/2006 00:14:57.437 0.000000

$\begin{array}{llr}1: 08: 41 \text { AM } & 52.3627 & 17.431 \\ 1: 09: 14 \text { AM } & 52.3627 & 17.431 \\ 1: 09: 46 \text { AM } & 52.3627 & 17.431 \\ 1: 10: 14 \text { AM } & 52.3627 & 17.431 \\ 1: 10: 45 \text { AM } & 52.3627 & 17.431 \\ 1: 11: 16 \text { AM } & 52.3627 & 17.431 \\ 1: 11: 48 \text { AM } & 52.3627 & 17.431 \\ 1: 12: 18 \text { AM } & 52.3627 & 17.431 \\ 1: 12: 49 \text { AM } & 52.3627 & 17.431 \\ 1: 13: 21 \text { AM } & 52.3627 & 17.431 \\ 1: 13: 53 \text { AM } & 52.3627 & 17.431 \\ 1: 14: 22 \text { AM } & 52.3627 & 17.431 \\ 1: 14: 53 \text { AM } & 51.7565 & 0 \\ 1: 15: 26 \text { AM } & 51.7565 & 0 \\ 1: 15: 57 \text { AM } & 51.7565 & 0 \\ 1: 16: 26 \text { AM } & 51.7565 & 0 \\ 1: 16: 57 \text { AM } & 51.7565 & 0 \\ 1: 17: 28 \text { AM } & 51.7565 & 0 \\ 1: 18: 01 \text { AM } & 51.7565 & 0 \\ 1: 18: 30 \text { AM } & 51.7565 & 0 \\ 1: 19: 01 \text { AM } & 51.7565 & 0 \\ 1: 19: 32 \text { AM } & 51.7565 & 0 \\ 1: 20: 04 \text { AM } & 51.7565 & 0 \\ 1: 20: 34 \text { AM } & 51.7565 & 0 \\ 1: 21: 05 \text { AM } & 51.7565 & 0 \\ 1: 21: 37 \text { AM } & 51.7565 & 0 \\ 1: 22: 11 \text { AM } & 51.7565 & 0 \\ 1: 22: 38 \text { AM } & 51.7565 & 0 \\ 1: 23: 10 \text { AM } & 51.7565 & 0 \\ 1: 23: 43 \text { AM } & 51.7565 & 0 \\ 1: 24: 11 \text { AM } & 51.7565 & 0 \\ 1: 24: 43 \text { AM } & 51.7565 & 0 \\ 1: 25: 14 \text { AM } & 51.7565 & 0 \\ 1: 25: 45 \text { AM } & 51.7565 & 0 \\ 1: 26: 17 \text { AM } & 51.7565 & 0 \\ 1: 26: 46 \text { AM } & 51.7565 & 0 \\ 1: 27: 17 \text { AM } & 51.7565 & 0 \\ & & \end{array}$

$\begin{array}{lll}0 & 10.9488 & 15.4391\end{array}$ $10.9488 \quad 15.4391$

$10.9488 \quad 15.4391$

$10.9488 \quad 15.4391$

$10.9488 \quad 15.4391$

$10.9488 \quad 15.4391$

$10.9488 \quad 15.4391$

$10.9488 \quad 15.4391$

$10.9488 \quad 15.4391$

$10.9488 \quad 15.4391$

$10.9488 \quad 15.4391$

$10.9488 \quad 15.4391$

$\begin{array}{ll}11.2426 & 15.4945\end{array}$

$11.2426 \quad 15.4945$

$11.2426 \quad 15.4945$

$11.2426 \quad 15.4945$

$11.2426 \quad 15.4945$

$11.2426 \quad 15.4945$

$11.2426 \quad 15.4945$

$11.2426 \quad 15.4945$

$11.2426 \quad 15.4945$

$11.2426 \quad 15.4945$

$11.2426 \quad 15.4945$

$11.2426 \quad 15.4945$

$11.2426 \quad 15.4945$

$11.2426 \quad 15.4945$

$11.2426 \quad 15.4945$

$11.2426 \quad 15.4945$

$11.2426 \quad 15.4945$

$11.2426 \quad 15.4945$

$11.2426 \quad 15.4945$

$11.2426 \quad 15.4945$

$11.2426 \quad 15.4945$

$\begin{array}{ll}11.2426 & 15.4945\end{array}$

$\begin{array}{lll}0 & 11.2426 & 15.4945\end{array}$

$\begin{array}{lll}0 & 11.2426 & 15.4945\end{array}$

$0 \quad 11.2426 \quad 15.4945$
0

0

0

0

0

0

0

0

0

0

0

0

0

0

0

0

0

0

0

0

0

0

0

0

0

0

0

0

0

0

0

0

0

0

0

0

0 